\title{
MicroRNA-214 in Health and Disease
}

\author{
Meer M. J. Amin (D, Christopher J. Trevelyan and Neil A. Turner *(i)
}

check for

updates

Citation: Amin, M.M.J.; Trevelyan, C.J.; Turner, N.A. MicroRNA-214 in Health and Disease. Cells 2021, 10, 3274. https://doi.org/10.3390/ cells10123274

Academic Editor: Ajit Vikram

Received: 22 October 2021

Accepted: 20 November 2021

Published: 23 November 2021

Publisher's Note: MDPI stays neutral with regard to jurisdictional claims in published maps and institutional affiliations.

Copyright: (c) 2021 by the authors. Licensee MDPI, Basel, Switzerland. This article is an open access article distributed under the terms and conditions of the Creative Commons Attribution (CC BY) license (https:// creativecommons.org/licenses/by/ $4.0 /)$.
Discovery and Translational Science Department, Leeds Institute of Cardiovascular and Metabolic Medicine, School of Medicine, University of Leeds, Leeds LS2 9JT, UK; meeramin64@gmail.com (M.M.J.A.); bs16cjt@leeds.ac.uk (C.J.T.)

* Correspondence: n.a.turner@leeds.ac.uk

\begin{abstract}
MicroRNAs (miRNAs) are endogenously expressed, non-coding RNA molecules that mediate the post-transcriptional repression and degradation of mRNAs by targeting their $3^{\prime}$ untranslated region ( $3^{\prime}$-UTR). Thousands of miRNAs have been identified since their first discovery in 1993, and miR-214 was first reported to promote apoptosis in HeLa cells. Presently, miR-214 is implicated in an extensive range of conditions such as cardiovascular diseases, cancers, bone formation and cell differentiation. MiR-214 has shown pleiotropic roles in contributing to the progression of diseases such as gastric and lung cancers but may also confer cardioprotection against excessive fibrosis and oxidative damage. These contrasting functions are achieved through the diverse cast of miR-214 targets. Through silencing or overexpressing miR-214, the detrimental effects can be attenuated, and the beneficial effects promoted in order to improve health outcomes. Therefore, discovering novel miR-214 targets and understanding how miR-214 is dysregulated in human diseases may eventually lead to miRNA-based therapies. MiR-214 has also shown promise as a diagnostic biomarker in identifying breast cancer and coronary artery disease. This review provides an up-to-date discussion of miR-214 literature by describing relevant roles in health and disease, areas of disagreement, and the future direction of the field.
\end{abstract}

Keywords: microRNAs; cardiovascular; cancer; bone; cell differentiation

\section{Introduction}

Advances in genomic techniques, such as next-generation sequencing (NGS), have revealed that only 1-2\% of the human genome encodes for proteins, as established by the ENCODE Project [1]. Despite this, $80 \%$ of the genome was deemed to have biological activity, which suggested that large regions had unknown functions not ascribed to protein coding. These elusive regions were largely referred to as non-coding RNAs (ncRNAs) and labelled as genetic 'junk' [2]. However, it has become increasingly apparent that ncRNAs perform major regulatory roles.

The most studied class of ncRNAs are the endogenously expressed, single-stranded microRNAs (miRNAs/miRs) which inhibit mRNA translation [3]. MiRNA processing involves cleavage by the Drosha and Dicer nucleases to form a miRNA:miRNA duplex,

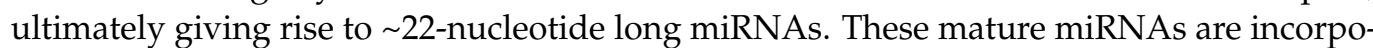
rated into the miRNA-induced silencing complex (miRISC), where miRNAs bind mostly to the $3^{\prime}$-untranslated regions ( $3^{\prime}$-UTRs) of mRNAs. This results in post-transcriptional suppression and reduces protein output. By manipulating the expression of multiple targets and gene networks, miRNAs can coordinate their effects to achieve a nuanced outcome, be it beneficial or detrimental. The combinatorial interactions between target genes and other miRNAs allows for a vast diversity of possibilities in modulating health and disease.

Lee and colleagues [4] discovered the first miRNA, called lin-4, in 1993, and it was found to regulate the temporal development of $C$. elegans. Many other miRNAs have since been identified, with 2300 miRNAs in humans alone [5]. As of 2018, 38,589 pre-miRNAs 
across 271 organisms had been catalogued in miRbase; a number that is continuously rising [6]. Due to their relatively recent discovery and their vast numbers, little is known about each individual miRNA. Research has thus aimed to characterise their roles, but this is challenging as miRNAs have multiple targets and their functions can overlap with one another. Additionally, the potency of miRNA suppression can be undetectable in some circumstances [7]. Nonetheless, their importance in mammalian physiology remains uncontested, as inhibiting miRNA processing impairs early development and induces embryonic lethality in mice $[8,9]$.

MiR-214 is encoded by an antisense ncRNA called Dynamin-3 opposite strand (Dnm3os) and was initially found to promote apoptosis in HeLa cells [10]. It has since been implicated in cardiovascular diseases, cancers, bone development and cell differentiation [11-13]. In the heart, miR-214 protects against $\mathrm{Ca}^{2+}$ ion overload [14] and oxidative damage [15], but downregulates angiogenesis [16], and potentially promotes pathological fibrosis [17,18]; although this is disputed [19-21]. MiR-214 variably affects cancer metastasis, proliferation and chemoresistance. It encourages gastric [22], ovarian [23], skin [24] and lung [25] cancer progression, but suppresses liver [16] and cervical [26] cancers. MiR-214 is also implicated in pancreatic cancer [27], myeloma [28] and nasopharyngeal carcinoma [29]. However, these lie outside the scope of this review, which instead focuses on cancers with abundant literature. MiR-214 also inhibits bone formation [30], and promotes the differentiation of skeletal [31] and vascular smooth muscle cells [32]. Not only does miR-214 act through a multitude of targets, but targets such as the tumor suppressor phosphatase and tensin homolog (PTEN) exhibit ubiquity in multiple conditions including oxidative stress [15], gastric and ovarian cancers [22,23], and T cell differentiation [33].

Unknowns surround the combinatorial interactions between miR-214 targets and other miRNAs. Additionally, large contradictions in the literature are yet to be settled, particularly in breast cancer [34,35], thus demanding more sensitive gain-of-function/lossof-function studies to draw a definitive line. Transfecting cells with anti-miR-214 and premiR-214 (antagomir/agomir-214) allows for the cell-specific effects of miR-214 knockdown or upregulation to be observed, respectively [36]. Microarray analyses also highlight dysregulated miRNAs, often indicating disease interactions for further study.

This review aims to provide a broad overview of the literature surrounding the roles of miR-214 in health and disease, first by outlining miRNA biogenesis. Cardiovascular health, cancers, bone formation and cell differentiation are then discussed in the context of miR-214. Understanding these roles helps realise the potential in modulating miR-214 for therapeutic benefit. For instance, inhibiting miR-214 relieves cardiac hypertrophy [37], metastatic melanoma [38], and osteoporotic defects [30,39]. Given the devastation of these diseases globally, it is paramount to discover novel therapies. The pathogenic roles of miR-214 mean it can double as a therapeutic target and as an attractive diagnostic marker to identify severe diseases, such as breast cancer [40] and coronary artery disease (CAD) [41]. By bringing together information on all these diseases, we aim to provide a broad picture of the regulation and function of miR-214 across tissues, including molecular detail from specific diseases that may also be relevant to seemingly unrelated diseases.

\section{MicroRNAs}

\subsection{Biogenesis and Action of MicroRNAs}

Processing miRNAs is a multistep process, as illustrated in Figure 1. When transcribed into primary miRNAs (pri-miRNAs), the RNase III Drosha nuclease cleaves pri-miRNAs to form $~ 70$-nucleotide pre-miRNAs [3]. Next, pre-miRNA is transported from the nucleus to the cytoplasm and is cleaved by the RNase III Dicer to form a duplex of $\sim 22$-nucleotide mature miRNAs [3]. Mature miRNAs are denoted with a $-3 p /-5 p$ suffix, depending on their origin from the $3^{\prime} / 5^{\prime}$ end of the pre-miRNA hairpin, and an asterisk has traditionally been used to distinguish the less prevalent form [3]. One strand from the duplex is preferentially loaded into Argonaute (Ago) proteins and forms the miRISC. The balance of miRNA$3 p / 5 p$ loading depends largely on cellular contexts. Most miRNAs are processed this way, 
however other pathways have been described. Introns can mimic pre-miRNA structures, known as 'mirtrons', to bypass Drosha/DGCR8 processing in flies and nematodes [42]. Alternatively, the miR-451 precursor is cleaved by Ago2 and matures independently of Dicer [43].

Through sequence complementarity, the $5^{\prime}$-end of miRNAs binds the $3^{\prime}$-UTR of target mRNAs for post-transcriptional suppression [3]. The degree of complementarity determines whether mRNAs are cleaved by Ago2 or targeted for degradation through miRISCmediated decapping and deadenylation. Interestingly, the $3^{\prime}$-end of miRNAs can target $5^{\prime}$-UTRs, so miRNAs could potentially target both $3^{\prime}$ - and $5^{\prime}$-UTRs [44].

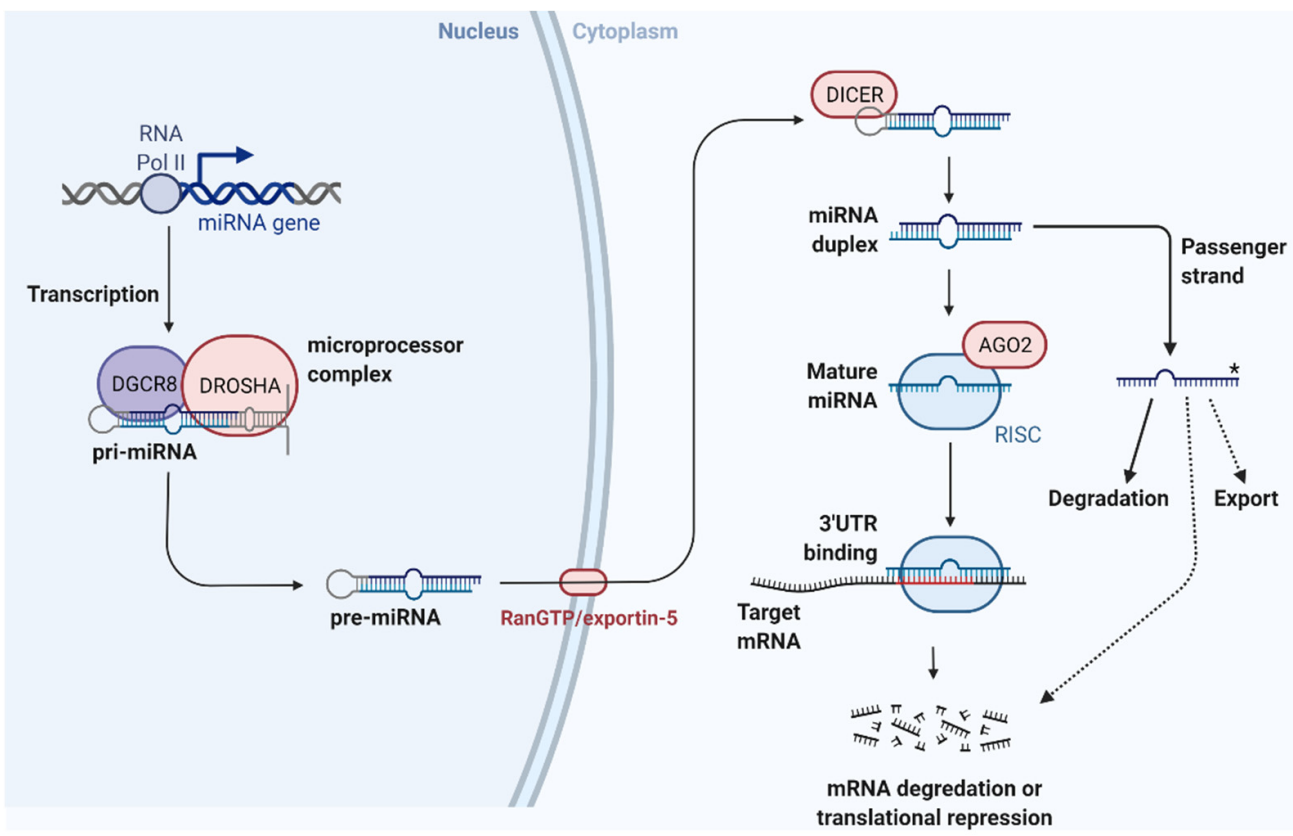

Figure 1. Classical miRNA biogenesis. RNA polymerases transcribe primary miRNAs (pri-miRNAs) which are then processed by the microprocessor complex minimally comprising RNase III Drosha nuclease with the RNA-binding DiGeorge Syndrome Critical Region 8 (DGCR8) cofactor. The resulting double-stranded precursor miRNA (pre-miRNA) is transported from the nucleus to the cytoplasm by RanGTP/exportin-5. A second RNase III nuclease called Dicer cleaves pre-miRNA at the stem-loop to form a miRNA:miRNA duplex. One strand from the duplex, known as the guide strand, is loaded into Ago proteins and the RNA-induced silencing complex (RISC). The other strand, called the passenger strand, is usually degraded, but in some cases may have functional activity within the cell, or be exported and act in a paracrine manner. The $5^{\prime}$-end of miRNA in the miRISC binds the $3^{\prime}$-UTR of target mRNAs by sequence complementarity. Messenger RNAs are then either translationally repressed or degraded. Adapted from 'microRNA in Cancer' by BioRender.com (2021). Retrieved from https:/ / app.biorender.com/biorender-templates (accessed on 16 November 2021). For details, see $[13,45]$.

\subsection{Investigating MicroRNAs}

High-throughput miRNA analysis is performed through microarrays, which profiles the expression of many miRNAs from tissue or fluid samples [45]. Quantitative realtime PCR (qRT-PCR) and Northern blotting quantifies specific miRNAs. Sensitive NGS and RNA-Seq can also identify novel miRNAs. Bioinformatic approaches using freely available databases (for example, miRBase.org and targetscan.org) can predict miRNA targets through analysing complementarity with $3^{\prime}$-UTRs. Predictions are further verified by Western blotting or luciferase assays, where the desired $3^{\prime}$-UTR is cloned into a luciferase reporter. A target is confirmed when luciferase expression is reduced upon introduction of the miRNA. 
For functional analysis, miRNAs can be downregulated or upregulated by transfecting antagomirs/anti-miRs with antisense complementarity, or agomirs which are pre-miRNA mimics, respectively [36]. Genetic deletion in transgenic animals allows for studying systemic miRNA underexpression. However, cell-specific knockdown or modifying promoters to overexpress miRNAs encourages more selective in vivo examinations. Alternatively, miRNA 'sponges' such as the long non-coding RNAs (lncRNAs) MALAT1 [46] and Xinactive specific transcript (XIST) [47] can occupy miRNA binding sites to prevent target interactions, without affecting expression. Manipulating miRNA expression can come with unintended effects, and studies must build a comprehensive understanding of miRNAs without over-reliance on just one method.

\subsection{MicroRNA-214}

Dnm3os is an antisense ncRNA conserved between vertebrates and was first identified within intron 14 of the DNM3 gene in mice; human DNM3 is in chromosomal region 1q24.3 [11,48] (illustrated in Figure 2). Mice with mutant Dnm3os exhibited developmental and skeletal defects, highlighting the essential role of Dnm3os [49]. Dnm3os encodes both pre-miR-199a and pre-miR-214, as evidenced by their downregulation in these Dnm3os mutants. Dnm3os is highly expressed during murine embryogenesis, and Loebel and colleagues [48] reported a downregulation of Dnm3os in embryos lacking the Twist transcription factor. This is corroborated by reduced miR-199a/miR-214 expression following Twist1 knockdown in ovarian cancer cells [50].

Dynamin-3 (Dnm3) gene, chromosomal region 1q24.3

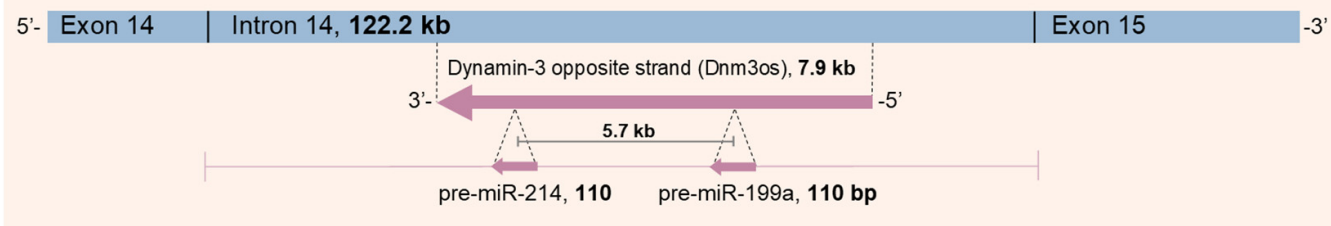

Figure 2. Illustration of the human DNM3 gene and the miR-214/199a cluster. Schematic representation of the $7.9 \mathrm{~kb}$ long DNM3os transcript within intron 14 of the DNM3 gene, encoded by the DNM3 complementary strand. DNM3os co-expresses the clustered pre-miR-214 and pre-miR-199a, which are $5.7 \mathrm{~kb}$ apart. Adapted from [12,51].

When co-transcribed, the miR-214/miR-199a cluster produces four mature miRNAs: the guide strands miR-199a-5p and miR-214-3p, and the passenger strands miR-199a-3p and miR-214-5p [11]. This review focuses on miR-214-3p (referred to as miR-214 throughout), however miR-214-5p (also termed miR-214*) is implicated in liver cancer [52], pancreatic cancer [53] and hepatic fibrosis [54]. More studies are required to understand how miR-214* interacts with miR-214. MiR-214 has now been characterised in cardiovascular diseases [11], cancers [12], osteogenesis [55] and myogenesis [56]. Table 1 summarises the discussed targets of miR-214 and their resulting effects.

Table 1. MiR-214 targets and associated effects. List of miR-214 targets discussed within this review and associated effects upon miR-214-mediated downregulation of the target mRNA / protein. Individual effects and corresponding references are separated by semicolons.

\begin{tabular}{cccc}
\hline $\begin{array}{c}\text { Target } \\
\text { mRNA/Protein }\end{array}$ & Effect Mediated by miR-214 Downregulation & Reference \\
\hline$\alpha 1$-AT & Promotes cell viability, invasion, and migration in triple-negative breast cancer. & [57] \\
\hline ATF4 & Inhibits osteoblast activity; inhibits osteoblast differentiation in hPDLSCs. & [30,58] \\
\hline R-catenin & $\begin{array}{c}\text { Reduced activation of pro-proliferative downstream effectors c-myc, TCF-1 and } \\
\text { cyclinD1 in hepatocellular carcinoma; inhibits breast cancer proliferation; inhibits } \\
\text { osteoblast differentiation. }\end{array}$ & [59-61] \\
\hline
\end{tabular}


Table 1. Cont.

\begin{tabular}{|c|c|c|}
\hline $\begin{array}{c}\text { Target } \\
\text { mRNA/Protein }\end{array}$ & Effect Mediated by miR-214 Downregulation & Reference \\
\hline$\alpha 1-\mathrm{AT}$ & Promotes cell viability, invasion, and migration in triple-negative breast cancer. & [57] \\
\hline ATF4 & Inhibits osteoblast activity; inhibits osteoblast differentiation in hPDLSCs. & {$[30,58]$} \\
\hline$\beta$-catenin & $\begin{array}{c}\text { Reduced activation of pro-proliferative downstream effectors c-myc, TCF-1 and } \\
\text { cyclinD1 in hepatocellular carcinoma; inhibits breast cancer proliferation; inhibits } \\
\text { osteoblast differentiation. }\end{array}$ & [59-61] \\
\hline $\mathrm{Bcl} 212$ & Inhibits cervical cancer growth. & {$[62]$} \\
\hline BIM & Inhibits mitochondrial-dependent apoptosis. & [14] \\
\hline СаMKII $\delta$ & Impairs the regulation of excitation-contraction coupling in the heart. & {$[14]$} \\
\hline CypD & Impairs the opening of the mitochondrial permeability transition pore. & [14] \\
\hline Ezh1 & Inhibits Col1 $\alpha 1$ and Col1 $\alpha 3$ expression in myofibroblasts. & [19] \\
\hline Ezh2 & $\begin{array}{l}\text { Promotes cardiac hypertrophy; inhibits Col1 } \alpha 1 \text { and Col1 } \alpha 3 \text { expression in } \\
\text { myofibroblasts; inhibits cervical cancer growth; inhibits breast cancer proliferation and } \\
\text { cell invasion; establishes a feedback loop to promote skeletal muscle cell differentiation. }\end{array}$ & {$[19,31,34,37,63]$} \\
\hline FGFR-1 & Inhibits cell invasion in hepatocellular carcinoma; inhibits osteoblast differentiation. & {$[64,65]$} \\
\hline FOXM1 & Inhibits cervical cancer growth, invasion and promotes cisplatin sensitivity. & [66] \\
\hline HDGF & Impairs angiogenic signalling in hepatocellular carcinoma. & {$[67]$} \\
\hline HMGA1 & Inhibits cervical cancer growth and invasion. & [68] \\
\hline ITGA3 & Increases melanoma cell migration. & [24] \\
\hline JNK1 & Inhibits proliferation and metastasis in cervical cancer and affects EGFR signaling. & [26] \\
\hline MEK3 & Inhibits cervical cancer progression. & [26] \\
\hline Mitofusin2 (Mfn2) & $\begin{array}{l}\text { Promotes ERK1/2-MAPK activation, cardiac fibroblast proliferation and } \\
\text { collagen synthesis. }\end{array}$ & [17] \\
\hline NCX1 & Attenuates calcium ion overload in the heart. & [14] \\
\hline NLRC5 & Inhibits cardiac fibroblast activation and fibroblast to myofibroblast transition. & [21] \\
\hline N-Ras & Promotes myogenic differentiation. & [69] \\
\hline Osterix & Inhibits osteoblast differentiation. & [70] \\
\hline p53 & Promotes breast cancer cell invasion. & [71] \\
\hline Plexin-B1 & Inhibits cervical cancer growth and invasion. & [72] \\
\hline
\end{tabular}

Inhibits PTEN signalling and promotes the PI3K/Akt pathway.

Protects against $\mathrm{H}_{2} \mathrm{O}_{2}$-mediated apoptosis in cardiomyocytes; promotes gastric cancer progression; promotes peritoneal metastasis in gastric cancer; promotes ovarian cancer

PTEN chemoresistance to cisplatin; promotes lung cancer resistance to gefitinib; promotes glycolysis in NSCLC; promotes cell growth and protects against apoptosis in breast cancer; promotes osteoclast differentiation; promotes regulatory $\mathrm{T}$ cell differentiation; increases $\mathrm{T}$ cell proliferation.

\begin{tabular}{ccc}
\hline Quaking & $\begin{array}{c}\text { Impairs angiogenic signalling; promotes vascular smooth muscle cell differentiation; } \\
\text { promotes neurogenesis during cerebral cortex development. }\end{array}$ & {$[32,77,78]$} \\
\hline RFWD2 & $\begin{array}{c}\text { Promotes apoptosis and sensitises breast cancer to doxorubicin. } \\
\text { [79] }\end{array}$ & $\begin{array}{c}\text { Inhibits metastatic epithelial-mesenchymal transition in breast cancer; encourages } \\
\text { chromosomal instability in ovarian cancer. }\end{array}$ \\
\hline RNF8 & $\begin{array}{c}\text { Impairs the Th1/Th2 cell balance in asthmatic patients when simultaneously targeted } \\
\text { by miR-214, miR-371, miR-138, miR-544, and miR-145. }\end{array}$ & [82] \\
\hline Runx3 & Promotes cell viability, invasion, migration, and epithelial-mesenchymal transition in \\
triple-negative breast cancer.
\end{tabular}


Table 1. Cont.

\begin{tabular}{|c|c|c|}
\hline $\begin{array}{c}\text { Target } \\
\text { mRNA/Protein }\end{array}$ & Effect Mediated by miR-214 Downregulation & Reference \\
\hline $\mathrm{Su}(\mathrm{fu})$ & $\begin{array}{l}\text { Activates hedgehog signalling and promotes muscle cell differentiation in zebrafish; } \\
\text { inhibits inflammatory smooth muscle cell differentiation. }\end{array}$ & {$[84,85]$} \\
\hline Survivin & Inhibits breast cancer proliferation and increases apoptosis. & [86] \\
\hline TFAP2C & $\begin{array}{l}\text { Increases melanoma cell migration and metastasis, increases progrowth VEGFA and } \\
\text { suppresses ERBB2, and regulates many more factors. }\end{array}$ & [24] \\
\hline TRAF3 & Promotes osteoclast activity and osteolytic bone metastasis in breast cancer patients. & [87] \\
\hline UCP2 & Sensitises breast cancer cells to tamoxifen and fulvestrant. & [88] \\
\hline XBP1 & Impairs angiogenic signalling; impairs hepatocellular carcinoma survival. & {$[16,89]$} \\
\hline Xotx2 & Inhibits retinal bipolar neuron differentiation. & [90] \\
\hline Xvsx1 & Inhibits retinal bipolar neuron differentiation. & [90] \\
\hline
\end{tabular}

\section{MicroRNA-214 in Cardiovascular Physiology and Pathophysiology}

The diverse effects of miR-214 on cardiovascular health and disease are summarised in Figure 3 and discussed in more detail below.

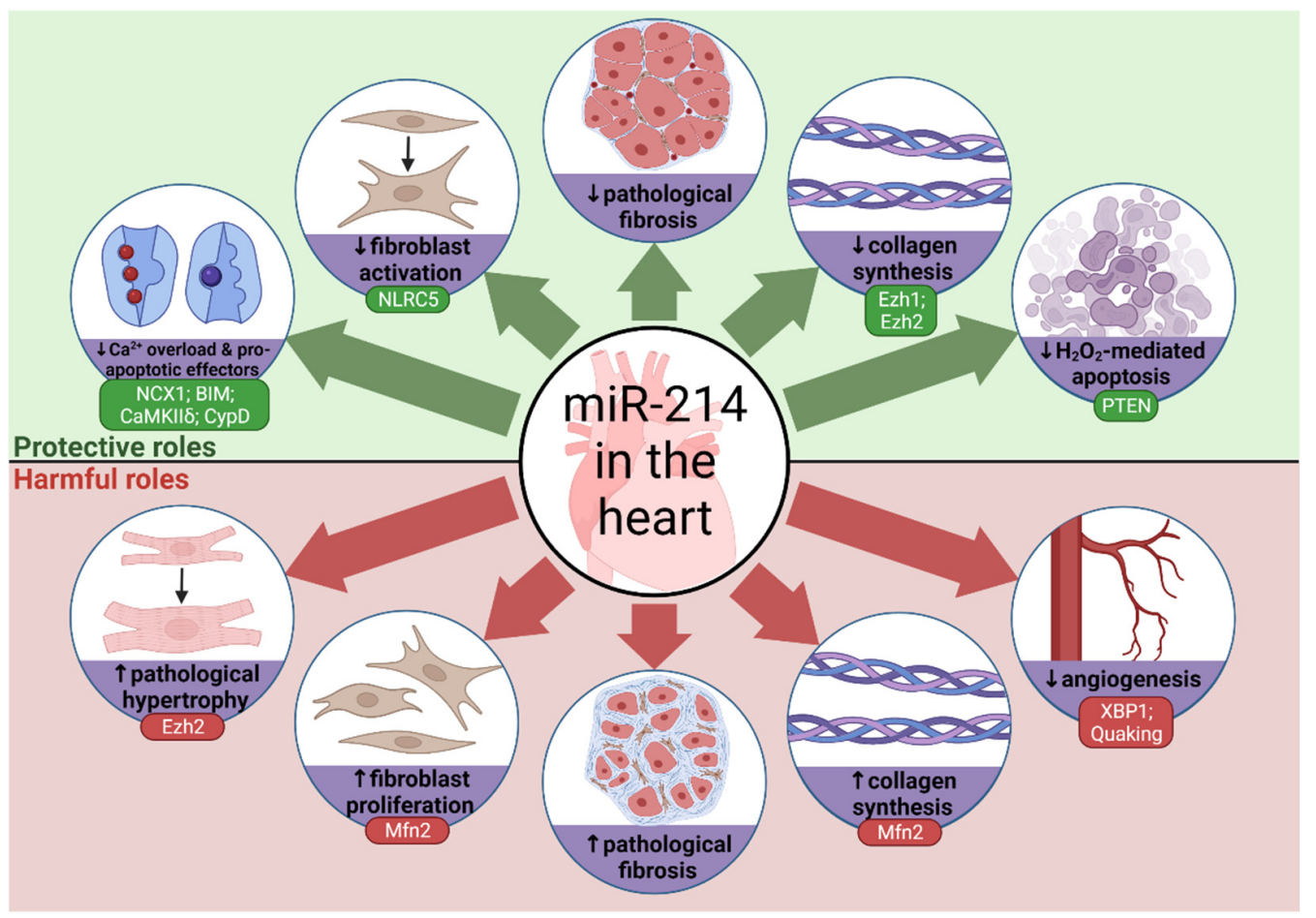

Figure 3. Effects of miR-214 on cardiovascular physiology. Summary of the protective and detrimental effects of miR-214 in the heart, with known target mRNA/proteins indicated, as discussed in the main text. Some effects only apply to specific cells or experimental conditions. See the main text of Section 3 for detailed information and references. Created with BioRender.com.

\subsection{Calcium Overload}

Calcium ions $\left(\mathrm{Ca}^{2+}\right)$ are well established in cardiac physiology, and rising intracellular $\mathrm{Ca}^{2+}$ is observed during ischemic/reperfusion (IR) injury [91]. Ischaemia results from inadequate blood supply to the cardiac tissue, and reperfusion causes damage upon reoxygenation. An overload of $\mathrm{Ca}^{2+}$ can cause heart failure and cardiomyocyte death through triggering mitochondrial-dependent apoptosis and autophagy during IR injury. 
The $\mathrm{Na}^{+} / \mathrm{Ca}^{2+}$ exchanger (NCX) maintains ion homeostasis, normally by transporting $\mathrm{Ca}^{2+}$ out of cardiomyocytes [92]. However, NCX can also reverse pump $\mathrm{Ca}^{2+}$ into cells. The direction of $\mathrm{Ca}^{2+}$ transport during ischaemia was heavily debated, but Tani and Neely [93] revealed links between $\mathrm{Na}^{+} / \mathrm{Ca}^{2+}$ and $\mathrm{Na}^{+} / \mathrm{H}^{+}$exchange. Increased $\mathrm{H}^{+}$(protons) from ischemic anaerobic processes forces the NCX to work in reverse to take excess $\mathrm{Na}^{+}$out of the cardiomyocyte and bring $\mathrm{Ca}^{2+}$ in, as illustrated in Figure 4. Imahashi and colleagues reported that NCX knockout $(\mathrm{KO})$ mice experienced less necrotic cell death, improved cardiac contractility and superior ATP metabolism [92]. This suggests the damaging nature of $\mathrm{Ca}^{2+}$ overload, where the absence of NCX may offer protection.

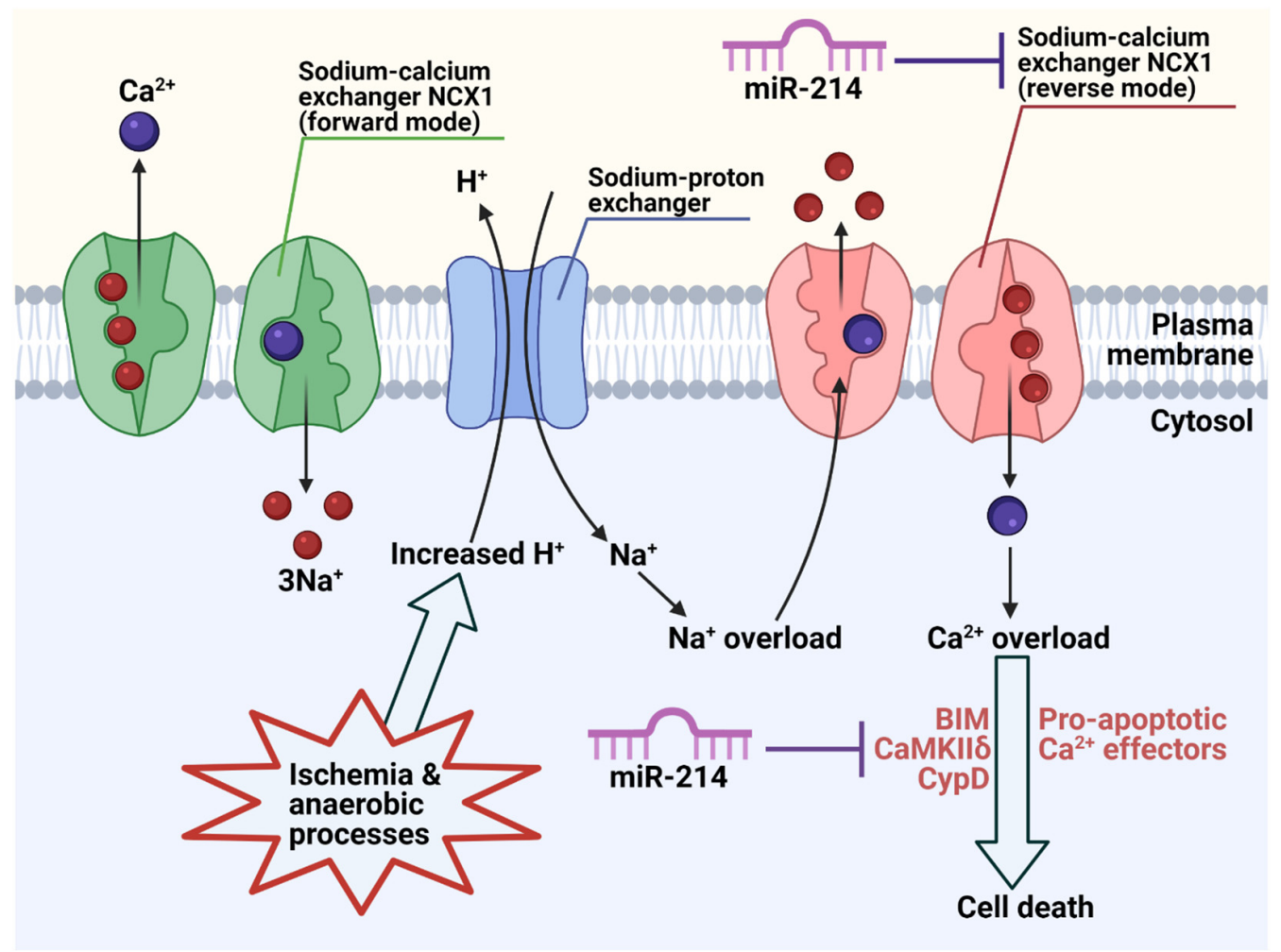

Figure 4. Calcium ion transport during ischaemic stress. The reversible sodium-calcium ion exchanger (NCX1) normally works in forward mode to take $\mathrm{Ca}^{2+}$ out of cells and bring $3 \mathrm{Na}^{+}$into cells. During ischaemia, anaerobic processes produce an excess of intracellular protons $\left(\mathrm{H}^{+}\right)$, which in turn stimulates sodium-proton exchange $\left(\mathrm{Na}^{+} / \mathrm{H}^{+}\right)$to remove $\mathrm{H}^{+}$from the cell and bring $\mathrm{Na}^{+}$ in. The resulting influx of $\mathrm{Na}^{+}$creates a $\mathrm{Na}^{+}$overload which stimulates NCX1 to act in reverse. Consequently, $3 \mathrm{Na}^{+}$are removed from the cell in exchange for bringing $\mathrm{Ca}^{2+}$ in. The overload of intracellular $\mathrm{Ca}^{2+}$ leads to cell death through the action of downstream proapoptotic effectors. $\mathrm{Ca}^{2+} /$ calmodulin-dependent protein kinase II delta (CaMKII $\delta$ ) is involved in excitation-contraction coupling. Bcl-2-like protein 11 (BIM) promotes mitochondrial-dependent apoptosis which can result from the opening of the mitochondrial permeability transition pore (mPTP), which is where CypD acts as a regulatory protein. MicroRNA-214 can target and inhibit the $3^{\prime}$-untranslated region ( $3^{\prime}$-UTR) of NCX1, thus preventing reverse transport and attenuating $\mathrm{Ca}^{2+}$ overload. Additionally, microRNA214 can directly target and inhibit BIM, CaMKII $\delta$ and CypD, altogether diminishing apoptotic cell death. Created with BioRender.com. Information from [14,92-94].

The role of miR-214 in IR injury was poorly defined until genetic loss-of-function studies showed that cardiac dysfunction and apoptosis were more apparent in miR-214 KO mice undergoing IR, indicating a protective function for miR-214 [14]. This appears contradictory to the findings of Cheng and colleagues who suggested that miR-214 promoted apoptosis in HeLa cells [10]. However, this is likely due to differences between in vitro and in vivo models, and the expression levels and importance of miR-214 in different cell types. 
Vila-Petroff and colleagues [95] found that inhibiting reverse mode NCX prevents IRmediated cardiomyocyte death. Supporting this, Aurora and colleagues [14] used luciferase assays to show that miR-214 targets the $3^{\prime}$-UTR of NCX1, and IR-induced apoptosis was increased in miR-214 KO cardiomyocytes. Additionally, increased intracellular $\mathrm{Ca}^{2+}$ in miR$214 \mathrm{KO}$ cardiomyocytes was observed when stimulating the reverse mode of NCX1 through exposure to high extracellular $\mathrm{Ca}^{2+}$. This suggests that cardiomyocytes are vulnerable to $\mathrm{Ca}^{2+}$ overload and IR injury in the absence of miR-214, as NCX1 is no longer repressed. Contradicting this, Hampton and colleagues [96] found NCX1 to protect against IR stress, where transgenic mice overexpressing NCX1 had better preserved cardiac function. Both studies are not antithetical, as the former focuses on miR-214 absence, while the latter analyses NCX1 overexpression. Additionally, NCX1 transport is secondary to sarcoplasmic reticulum activity, so the full scope of $\mathrm{Ca}^{2+}$ homeostasis should be considered in future studies. Some studies favour NCX1 in withstanding cardiac stress [96,97], while others suggest NCX1 exacerbates $\mathrm{Ca}^{2+}$ overload and cardiac damage [14,92,93,95]. Discrepancies may be due to inconsistent cardiac stress conditions, and the organisms or cells tested.

Nonetheless, additional cardiac protection is demonstrated by miR-214 targeting downstream $\mathrm{Ca}^{2+}$ effectors like cyclophilin D (CypD), Bcl-2-like protein 11 (BIM) and $\mathrm{Ca}^{2+} /$ calmodulin-dependent protein kinase II delta (CaMKIIס) [14], as shown in Figure 4. In miR-214 KO mice, all three effectors had elevated expression. Furthermore, luciferase constructs confirmed that miR-214 targets the $3^{\prime}$-UTR of genes encoding CaMKII $\delta$ and CypD, but surprisingly this was not seen with BIM. BIM was later identified as a direct target of miR-214 in nasopharyngeal carcinoma [94], although further verification would solidify these findings. CaMKII $\delta$ regulates excitation-contraction coupling and inhibiting CaMKII $\delta$ reduces the death of cardiomyocytes during IR injury, suggesting a detrimental role of CaMKII $\delta$ in the heart [95]. BIM is a member of the Bcl-2 family which promotes mitochondrial-dependent apoptosis [14]. Furthermore, $\mathrm{Ca}^{2+}$ overload can open the mitochondrial permeability transition pore (mPTP), through which proapoptotic cytochrome c is released [98]. CypD is a regulatory protein in the $\mathrm{MPTP}$, and CypD KO mice increases the difficulty for $\mathrm{Ca}^{2+}$ to open the MPTP, as reviewed in [99]. Overall, the absence of miR-214 which encourages reverse NCX1 transport, accumulation of intracellular $\mathrm{Ca}^{2+}$ and expression of proapoptotic effectors, suggests that miR-214 protects against IR injury and cardiomyocyte death. This presents potential therapeutic applications for cardiac damage using miR-214.

\subsection{Reactive Oxygen Species}

Cardiac damage during IR injury is further exacerbated through reactive oxygen species (ROS), which are primarily produced from complex I and III of the mitochondrial electron transport chain [100]. In the cardiovascular system, ROS plays a major pathological role. A detrimental cycle occurs when ischaemia damages the mitochondrial electron transport chain resulting in electron leakage, which helps generate free radicals from residual oxygen and then the newly generated ROS impairs the mitochondria even further [101]. Moreover, ROS can trigger apoptosis by opening the mPTP to release proapoptotic cytochrome c [98]. ROS generation can occur in cardiomyocytes at the onset of ischaemia, as well as with reperfusion [102].

Regarding miR-214, one study revealed that it confers cardioprotection against ROSmediated damage, specifically hydrogen peroxide $\left(\mathrm{H}_{2} \mathrm{O}_{2}\right)$ [15]. Previously, associations between miR-214 and $\mathrm{H}_{2} \mathrm{O}_{2}$ were poorly defined. However, miR-21 had exhibited protection against $\mathrm{H}_{2} \mathrm{O}_{2}$, suggesting the involvement of other miRNAs [103]. $\mathrm{H}_{2} \mathrm{O}_{2}$ increased apoptosis rates in rat cardiomyocytes and miR-214 levels were elevated in response to $\mathrm{H}_{2} \mathrm{O}_{2}$ exposure, signifying a protective role for miR-214 [15]. Flow cytometry revealed that transfecting cardiomyocytes with anti-miR-214 increased $\mathrm{H}_{2} \mathrm{O}_{2}$-mediated apoptosis. Additionally, PTEN levels and apoptosis decreased with pre-miR-214 transfection. These findings support the conclusion that miR-214 is stimulated upon $\mathrm{H}_{2} \mathrm{O}_{2}$ exposure, and targets PTEN to protect cardiomyocytes from $\mathrm{H}_{2} \mathrm{O}_{2}$-mediated apoptosis. However, no 
luciferase assays were carried out, thus leaving it to other studies to confirm that miR-214 directly targets PTEN [22]. Interestingly, miR-214 could potentially exacerbate oxidative stress in the aging murine liver, as detoxifying glutathione S-transferase levels negatively correlated with miR-214 [104]. However, functional evidence of miR-214 is required in addition to investigating other aging organs, such as the heart.

PTEN was first identified in 1997, where it was characterised as a tumour-suppressor gene located on the chromosome region 10q23 [105]. Shortly after, it was reported that PTEN suppressed cell migration and spreading [106]. PTEN may also promote caspase-3 expression to induce tumour cell apoptosis in gastric cancer [107]. Furthermore, decreased PTEN expression was associated with elevated cell motility and tumourigenic angiogenesis. Therefore, miR-214-targeting of PTEN is clinically relevant in cancer progression and presents therapeutic possibilities for ROS-mediated cardiac damage.

\subsection{Hypertrophy and Angiogenesis}

MiR-214 in IR injury has been well described, but uncertainty surrounds miR-214 in non-ischaemic cardiac damage. Multiple miRNAs, including miR-214 were upregulated in hypertrophic mouse hearts, suggesting links between miRNAs and hypertrophy $[18,108,109]$. Hypertrophy leads to enlarged cardiac tissue, often in response to stress, e.g., myocardial infarction, hypertension or physical exercise [110]. Protein synthesis is increased, and growth factors are secreted to bolster cardiac contractility. Increased myocardial mass demands greater oxygenation, and angiogenic signalling helps meet these demands by forming new blood vessels from pre-existing structures. Angiogenesis is regulated by factors such as vascular endothelial growth factor (VEGF) and placental growth factor (PLGF). Without proper angiogenesis in a hypertrophic heart, hypoxia occurs due to inadequate vascular oxygen delivery, eventually resulting in heart failure.

Significant miR-214 upregulation was reported in human heart failure patients and in hypertrophic mice hearts [16], which agrees with previous studies [108,109]. This suggests a pathological role of miR-214 in hypertrophy. Luciferase assays confirmed that miR-214 targeted the 3'-UTR of Ezh2, a repressor of cardiac hypertrophy [37]. Here, antagomir-214 rescued mice from pathological hypertrophy, therefore highlighting the therapeutic benefits of miR-214 inhibition in pressure-overloaded hearts.

During stimulated hypertrophy, miR-214 inhibition increased vascular density [16]. $\mathrm{X}$-box binding protein (XBP1) was found to be targeted by miR-214 here, as evidenced by luciferase assays in human umbilical vein endothelial cells (HUVECs). XBP1 is a transcription factor that regulates cell growth and resolves ER stress via the unfolded protein response. Overexpressing XBP1 upregulated tube formation in HUVECs, and transfection of XBP1 rescued cells from anti-angiogenic miR-214. XBP1 is also involved in inflammation and energy metabolism, thus prompting study into other effects of miR-214. This experiment is limited to HUVECs, so miR-214 in different cell types should be examined in the future to support these findings. Nonetheless, there is agreement with other studies. The pro-angiogenic factor Quaking is targeted by miR-214, and silencing miR-214 increases angiogenic cell sprouting during murine retinal development [77]. MiR-214 also inhibits angiogenesis in human hepatocellular carcinoma (HCC) [67]. Pro-angiogenic ginsenoside-Rg1 is a component of the Chinese medicine ginseng, and it downregulated miR-214 and upregulated the angiogenic regulator endothelial nitric oxide synthase (eNOS) in HUVECs [111]. Further studies should investigate whether miR-214 directly antagonises eNOS.

Finally, Lu and colleagues [41] discovered that circulating miR-214 was reduced in patients with CAD. Therefore, miR-214 could act as a diagnostic biomarker for identifying CAD. Moreover, the expression of pro-angiogenic PLGF was increased, indicating another potential miR-214 target. However, cautious interpretation is recommended, firstly because of the small sample size. Secondly, circulating miR-214 can fluctuate with differential expression and uptake by cells. Future studies should examine circulating miR-214 levels, ideally with a larger cohort of CAD patients. Altogether, abundant research evidences the anti-angiogenic properties of miR-214. Downregulating cardiac angiogenesis leads to hy- 
pertrophic hearts being unable to maintain function under stress, ultimately leading to heart failure. These studies support the development of therapies based on blocking miR-214 to reverse insufficient angiogenesis. Targeting miR-214 has been tested in vivo, where adenoassociated virus serotype 9 (AAV9)-mediated delivery of anti-miR-214 restored cardiac function in hypertrophic mouse hearts [16]. Conversely, upregulating miR-214 could be of value to attenuate harmful tumour angiogenesis. More work is needed on in vivo models and cultured human cells before taking miR-214 to clinical settings, however.

\subsection{Fibrosis}

Cardiac reparative fibrosis is a normal process of remodelling following damage such as IR injury or acute myocardial infarction (AMI) [112]. Fibrosis is primarily mediated by cardiac fibroblasts and the deposition of extracellular matrix (ECM) components in the myocardium $[112,113]$. The ECM is a complex network critical for connecting cells, strengthening cardiac structure, dissipating mechanical force, and distributing electrical signals. The deposition of fibrillar collagen, a major ECM component, replaces dead cardiomyocytes and allows myocardial remodelling to restore contractility following damage. Increased type I and type III procollagen mRNA was observed in an early study on infarcted rat hearts [114]. However, fibrosis can be detrimental when the synthesis and degradation of the ECM components is imbalanced [115]. Reactive fibrosis in a pressure-overloaded heart results in an overproduction of growth factors to support myocytes in response to an increased workload. This can cause stiffened ventricles and dysfunctional diastolic relaxations and systolic contractions. Conversely, collagen breakdown by matrix metalloproteinases (MMPs) likely accelerates the progression of left ventricular hypertrophy to heart failure [116].

The primary effector cells of cardiac fibrosis are fibroblasts, which are well established in synthesising and degrading ECM components [112,113]. Fibroblasts can differentiate into mobile myofibroblasts that contract collagen and express alpha-smooth muscle actin $(\alpha-S M A)$ to facilitate wound closure. Fibroblasts can secrete cytokines and growth factors such as interleukin-1 $\beta$ (IL-1 $\beta$ ), IL-6, and tumour necrosis factor- $\alpha$ (TNF- $\alpha)[117,118]$. Introducing IL-1 $\beta$ and TNF- $\alpha$ to rat cardiac fibroblasts decreased collagen synthesis and increased MMP expression, overall, promoting collagen turnover [119]. Similarly, increased ECM turnover was seen when exposing fibroblasts to oxidative stress such as $\mathrm{H}_{2} \mathrm{O}_{2}$ [120]. Understanding the regulation of ECM components may highlight novel drug targets.

Hou and colleagues [121] observed miRNA expression being mediated by $\beta$-adrenergic receptor ( $\beta$-AR). Isoproterenol (ISO) is a $\beta$-AR agonist, whereas propranolol antagonises $\beta$-AR. Hearts from ISO-treated rats mostly had upregulated miRNAs, including miR-214, and downregulation was prevalent in the propranolol group. This suggests that miRNAs are promoted by $\beta$-AR signalling. Additionally, the inhibition of $\beta$-AR signalling by HIP-55 impaired the ERK1/2-MAPK pathway and cardiac fibroblast proliferation during ISO treatment [122]. Moreover, overexpressing $\beta$-AR in transgenic mice resulted in cardiac hypertrophy and large fibrotic regions [123].

In agreement with Hou and colleagues [121], miR-214 was upregulated upon ISO treatment in mice [17]. Luciferase assays from this study showed that miR-214 targeted mitofusin2 (Mfn2), an inhibitor of the proliferative ERK1/2-MAPK pathway [17]. MiR214 knockdown via antagomir-214 significantly decreased ISO-induced cardiac fibroblast proliferation and collagen synthesis, and the opposite was shown with agomir-214. This suggests that miR-214 could promote pathological fibrosis through enhanced fibroblast proliferation and collagen deposition. Additionally, in our own study, fibroblast-specific $\mathrm{KO}$ of $\mathrm{p} 38 \alpha \mathrm{MAPK}$ in mice attenuated the ISO-mediated upregulation of miR-214 and detrimental fibrotic remodelling, suggesting a pathological role for miR-214 in fibrosis [18]. Similarly, Denby and colleagues [124] found that antagonising miR-214 through genetic deletions and antagomirs diminishes renal fibrosis. Intriguingly, miR-214* is also associated with liver fibrosis [54]. Overexpressing miR-214* upregulated MMPs and $\alpha$-SMA in human liver cells, thus prompting further investigation of miR-214*. 
Despite these findings, recent studies have reported that miR-214 confers cardioprotection against fibrosis. In vivo, the fibroblast-specific genetic deletion of miR-214 resulted in greater collagen deposition and fibrosis when mice were subjected to transverse aortic constriction (TAC); a technique to simulate cardiac hypertrophy [21]. The same study showed that miR-214 inhibited fibroblast activation in vitro by targeting the NOD-like receptor family CARD domain containing 5 (NLRC5). Upon fibrosis-inducing angiotensin-II treatment, the transfection of pre-miR-214 into cardiac fibroblasts led to reduced collagen I/III and pro-fibrotic transforming growth factor- $\beta 1$ (TGF- $\beta 1$ ) expression [20]. Similar observations were also seen with in vivo AMI models. This was supported by Zhu and colleagues, who reported a reduction in cardiac fibrosis with agomiR-214 in angiotensin-II treated mice [19]. In addition, miR-214 inhibited collagen type I alpha 1 and 3 (Col1a1, Col1a3) expression in myofibroblasts by targeting Ezh1 and Ezh2; the enzymatic components of the transcription-suppressing PcG proteins [19]. Together, these studies, through in vitro and in vivo models, have shown that miR-214 attenuates cardiac fibrosis. This is a strong hypothesis, and it suggests a therapeutic benefit in promoting miR-214 for fibrotic protection, however the findings of Sun and colleagues [17] remain contradictory. A likely explanation for this may be the unique stimuli in different cardiac models and tissue-specific phenotypes. The neurohumoral stimulation of $\beta$-AR by ISO differs from TAC which mimics a pressure-overloaded heart, and this differs from AMI models which simulate ischaemia/reperfusion. AMI is potentially more likely to induce reparative fibrosis, whereas ISO/TAC models encourage reactive fibrosis. Future studies should clarify these disagreements with further in vivo models to replicate multiple fibrotic environments. The discrepancies between miR-214 knockdown by antagomirs or genetic deletions should also be explored.

\section{MicroRNA-214 in Cancer Progression}

The various effects of miR-214 on cancer progression are summarised in Figure 5 and discussed below.

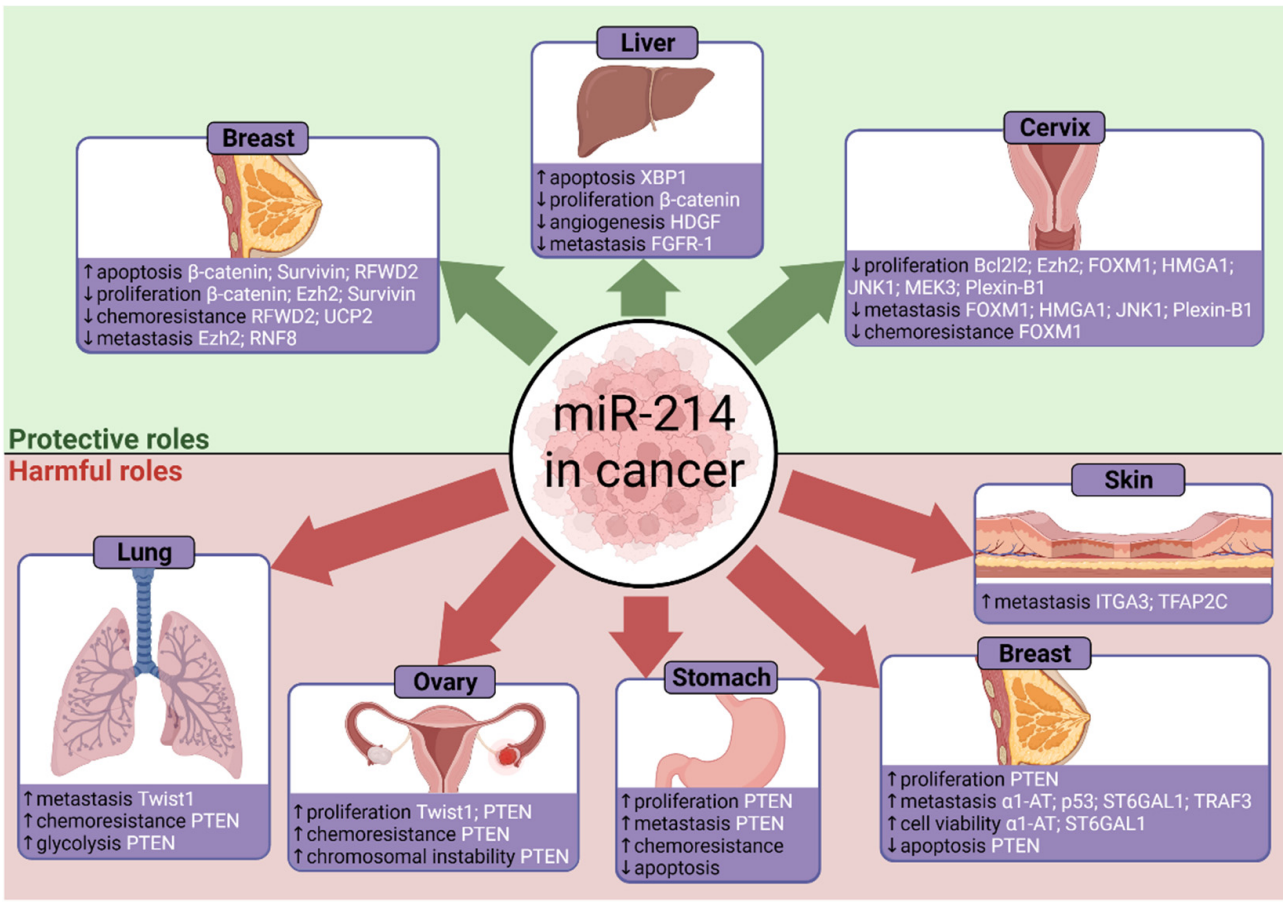

Figure 5. Effects of miR-214 on cancer progression. Summary of the protective and detrimental effects of miR-214 on cancer progression, with known target mRNA/proteins indicated, as discussed in the main text. Note that Twist1 is an exception as it is not targeted by miR-214 but instead modulates and 
upregulates miR-214 to achieve the corresponding effects. Some effects only apply to specific cells or experimental conditions. See the main text of Section 4 for detailed information and references. Created with BioRender.com.

\subsection{Gastric Cancer}

According to 2018 GLOBOCAN estimates, gastric cancer caused 783,000 deaths worldwide [125]. It is the third leading cause of cancer deaths behind colorectal and lung cancers. Aside from nutrition and alcohol intake, the bacterium Helicobacter pylori remains the leading risk factor for gastric cancer. Infection with $\mathrm{H}$. pylori causes gastritis and inflames the stomach lining and epithelial cells; this causes ulcers and eventually leads to gastric adenocarcinomas. Interestingly, eradicating $\mathrm{H}$. pylori can prove detrimental. Gastric cancers are classified into cardia and non-cardia subtypes. Over $90 \%$ of non-cardia cases are associated with $\mathrm{H}$. pylori, however the bacterium has shown protection against cardia-type cancers by reducing acid secretion and oesophageal gastritis. Hence, eradication of $\mathrm{H}$. pylori reduces non-cardia incidence but increases the prevalence of cardia cancers [125]. Emphasising diet and lifestyle modifications is likely a better alternative which has seen noticeable reductions in gastric cancer mortality [126].

Analysing microarrays from 353 human gastric cancer samples found that high miR214 expression correlated with a low patient survival [127]. This suggests that miR-214 modulates cancer, however the underlying mechanisms were unknown at the time. Additionally, this study was limited by only taking samples from Japan, and the patient demographic could lead to genetic bias in miRNA expression profiles. Nevertheless, this prompted further study of miR-214 in gastric cancer.

Supporting the findings of Lv and colleagues [15], who found that the tumour suppressor PTEN was downregulated upon miR-214 overexpression, Yang and colleagues reported similar observations from RT-PCR of human gastric cancer tissues [22]. Additionally, miR-214 correlated with poor clinical outcomes and metastatic gastric cancer, which is consistent with other reports [127]. Luciferase assays confirmed that miR-214 targets PTEN, and silencing PTEN by RNA interference attenuated the anti-miR-214-mediated inhibition of proliferation and migration [22]. This suggests miR-214 downregulates PTEN signalling to hasten gastric cancer progression. These findings present therapeutic interventions without eradicating H. pylori, as suppressing miR-214 could impair proliferation and metastasis. More recently, Xin and colleagues demonstrated strong correlations between miR-214 downregulating PTEN with increased peritoneal metastasis in human gastric cancer cells [73]. A separate study associated PTEN with promoting apoptosis through capase-3 in gastric cancer, suggesting that miR-214-mediated targeting of PTEN could inhibit antitumourigenic apoptosis [107]. Finally, miRNAs often have multiple targets, so outcomes are multifactorial. In zebrafish, it was discovered that miR-214 inhibited the suppressor of fused, or $\mathrm{Su}(\mathrm{fu})$ [84]. This activates hedgehog signalling which is involved in regulating cell differentiation and gastric cancer progression, as reviewed in [128].

Another significant aspect of gastric cancer mortality is chemotherapy resistance (chemoresistance) [129]. This includes resistance to cisplatin (DDP) which impairs DNA replication in cancerous cells. Resistance is brought about by uptake/efflux transporters, functional changes in drug targets, enhanced DNA repair, and evasion of apoptosis. Remarkably, DDP resistance in gastric cancer can be reversed by delivering anti-miR-214 in membrane-derived vesicles (exosomes), resulting in reduced tumour sizes and increased apoptosis in mice [130]. Exosomes bypass the cytotoxicity and poor delivery seen in conventional viral or liposomal vectors. Despite this, the molecular mechanisms for miR214-mediated chemoresistance in gastric cancer are not well known, thus demanding additional study. Eventually, this may enhance patient response to chemotherapy and reduce mortality rates. 


\subsection{Liver Cancer}

Hepatocellular carcinoma (HCC) is the most common primary liver cancer [125]. Globally, liver cancer was estimated to cause 782,000 deaths in 2018, making it the fourth deadliest cancer. Risk factors include hepatitis type B or C viruses (HBV, HCV), and lifestyle choices like smoking and diet.

In HCC cell lines, miR-214 was downregulated in $65 \%$ of cases [89], with similar observations reported in HCC samples [67]. XBP1, a regulator of the UPR, was again identified as a miR-214 target in HCC cell lines [89]. The UPR responds to ER stress resulting from the damaging accumulation of misfolded proteins, and XBP1 is important for tumour survival under stressful conditions like hypoxia. IRE1 splices an intron from XBP1 pre-mRNA to activate XBP1. In mice, XBP1 knocks out severely impaired tumour growth during hypoxia [131]. Similarly, inhibiting IRE1 in myeloma cells diminishes active XBP1, thus increasing their sensitivity to apoptosis during ER stress [132]. Future studies should investigate other UPR pathways like PKR-like ER kinase (PERK) or ATF6.

Nuclear factor- $\mathrm{kB}(\mathrm{NF} \kappa \mathrm{B})$ is a critical transcription factor that induces expression of cytokines and proinflammatory factors, and is involved in proliferation, apoptosis, inflammation, and immunity [133]. Normally, NFKB remains inactive in the cytoplasm by being

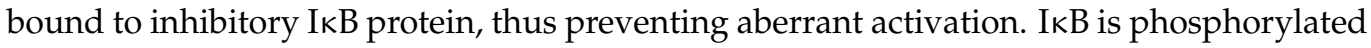
when stimulated by factors like lipopolysaccharide (LPS) or viral components, thereby releasing inhibition of $\mathrm{NF} \kappa \mathrm{B}$ so it can migrate to the nucleus to bind promoters and upregulate gene expression. In hypoxia, greater NF $\kappa B$ activation correlated with increased $I \kappa B$ phosphorylation, suggesting cells respond to stress via NFKB signalling [134]. Additionally, $\mathrm{NF} \kappa \mathrm{B}$ may confer protection in $\mathrm{HCC}$ cell lines undergoing oxidative stress with $\mathrm{H}_{2} \mathrm{O}_{2}$ [133].

In HCC cell lines, miR-214 reduced proliferation and increased apoptosis [89]. Similar observations were found in vivo with agomir-214-treated mice. In this study, inducing the UPR or stimulating NFKB with LPS resulted in reduced miR-214. Conversely, inhibiting $N F \kappa B$ attenuated the downregulatory effects of the UPR on miR-214. Together, this suggests that the UPR downregulates miR-214 by activating NFKB. This prevents miR-214-mediated tumour suppression and XBP1 downregulation, thus encouraging HCC progression. This is consistent with Romero-Ramirez and colleagues who demonstrated the importance of XBP1 in tumour survival [131]. In cardiac myofibroblasts, NFKB signalling was instead found to upregulate miR-214 upon angiotensin-II treatment [19]. However, this contradiction is likely due to differing cell types. Interestingly, miR-214* can also suppress HCC metastasis, thus revealing another therapeutic possibility [52].

An abundance of studies has revealed other miR-214 targets, such as $\beta$-catenin [59]. Overexpressing miR-214 inhibits HCC growth, as confirmed in vivo from mice exhibiting smaller tumours. Notably, the expression of $\beta$-catenin and its downstream effectors were suppressed, including c-myc, TCF-1 and cyclin D1. In $43 \%$ of in vivo HCC samples, $\beta$-catenin accumulated in the nucleus where it activates the transcription of proproliferative genes like c-myc and cyclin D1 [135]. Investigating oncogenic $\beta$-catenin mutations with larger sample sizes can help understand HCC progression. Another miR-214 target is hepatoma-derived growth factor (HDGF), which promotes hypervascularity [67]. Here, miR-214 suppressed angiogenic tube formation in vivo and in vitro. Finally, fibroblast growth factor receptor 1 (FGFR-1) was downregulated and targeted by miR-214 in HCC, with cell invasion being reduced by $>50 \%$ [64]. The diversity of targets in HCC suggest that others exist for future studies to identify, alongside potential combinatorial interactions between targets. Taken together, miR-214 acts to suppress HCC progression as it inhibits proliferation, tumour growth, angiogenesis, and metastasis through targeting XBP1, $\beta$-catenin, HDGF and FGFR-1. Overexpressing miR-214 is therefore an attractive strategy for countering HCC.

\subsection{Ovarian Cancer}

Ovarian cancer was estimated to cause over 180,000 deaths in 2018 [125], with a greater proportion of deaths:cases than cervix or uterine cancers. Risk factors include age, 
menstruation cycles, endometriosis, diet and obesity, among others. Epithelial ovarian cancer (EOC) is the most common subtype, with the tumour originating from epithelial cells [136]. EOC cell populations are characterised as chemoresistant, self-renewing type I cells or matured type II cells [50]. Stem cell-like type I cells can differentiate into type II cells, and understanding this transition is important to tackle recurrent tumours.

In human ovarian tumours, miR-214 was one of the most commonly upregulated miRNAs [23]. PTEN was found to be targeted by miR-214 here, and downregulating PTEN increases phosphorylation of the prosurvival Akt pathway. Consequently, miR-214 promoted cisplatin chemoresistance, thereby encouraging tumour recurrence. However, a larger sample size of ovarian tumours would help provide more evidence. MiR-214 also targets and downregulates the ubiquitin ligase RNF8 to impair the DNA damage response and promote tumourigenic chromosomal instability in ovarian cancer cells [81].

Twist 1 is a transcription factor that regulates cell differentiation, inflammation, and apoptosis [51]. Importantly, Twist1 was shown to regulate the expression of the miR199a/miR-214 cluster during embryonic mice development. Furthermore, several studies have observed the parallel expression of miR-214 and miR-199a in ovarian cancer, where they are both increased [23] or both decreased [137], indicating that these miRNAs are clustered.

Expression of both miR-199a and miR-214 was elevated in type II EOC cells but decreased in type I cells [50]. Moreover, Twist1 expression was higher in type II cells. Knockdown of Twist1 correlated with decreased miR-199a/miR-214 expression, suggesting that Twist1 upregulates miRNA expression. Interestingly, Twist1 can negatively modulate NFKB signalling by upregulating miR-199a, which targets IKK $\beta$. Later research identified that miR-214 is negatively regulated by the NFKB pathway in $\mathrm{HCC}$, so a similar mechanism may exist in ovarian cancer [89]. Additionally, greater levels of phosphorylated-Akt and decreased PTEN were seen in mature type II cells, where miR-214 is more prevalent [50]. Overall, Twist1 is a complex modulator of the miR-199a/214 cluster, where it downregulates inflammatory NFkB signalling and upregulates pro-proliferative Akt signalling. Remarkably, inhibiting Twist1 can restore stem-cell-like properties in mature type II cells. Indeed, the in vitro differentiation of type I to type II cells correlated with increased Twist1, thus accelerating EOC progression by promoting proliferative cell phenotypes. Increased Akt signalling by miR-214 targeting PTEN was also confirmed by another group [23]. Manipulating miR-199a/miR-214 regulation and preventing Twist1 activity could ultimately slow down EOC development.

\subsection{Cervical Cancer}

Cervical cancer is the fourth leading cause of cancer death in women with over 300,000 global deaths in 2018 [125]. It is more common in less developed countries, partially due to poor screening and vaccination programmes. Vaccinations counter the high-risk human papillomavirus (HPV) subtypes, like HPV-16 and HPV-18. These viruses promote genetic instability and the degradation of tumour suppressors like p53 through their E6 and E7 proteins [138]. Ultimately, HPV facilitates cervical cancer progression and mortality.

Several miRNAs were reported to be dysregulated in human cervical cancer cells [139]. Furthermore, miR-143 and miR-145 suppressed proliferation in HeLa cells, whereas miR146a promoted growth. It is plausible that miR-214 plays a role in cervical cancer, especially as it is dysregulated in ovarian cancer [23]. Supplementing the findings of Wang and colleagues [139], another study observed miR-214 downregulation in vivo and in vitro with human cervical cancer tissues and HeLa cells [26]. Similarly, low miR-214 expression was reported in HeLa cells containing HPV-16 DNA [138]. However, it should be noted that HeLa cells are not directly comparable to tissue samples, as these cells have been cultured over a long period of time and have altered genetically.

MiR-214 mediates the antiproliferative effects by targeting MEK3 and c-Jun N-terminal kinase 1 (JNK1) mRNAs, as verified by luciferase assays [26]. A recent study showed that the E6 oncogene of HPV activates JNK1 signalling to promote cell proliferation and metas- 
tasis in cervical cancer, partially from JNK1 upregulating epidermal growth factor receptor (EGFR) signalling [140]. Meanwhile, MEK3 activates the p38 MAPK pathway to promote apoptosis [141]. Cervical tumour suppression can therefore occur from miR-214 downregulating JNK1. However, miR-214 targets proapoptotic MEK3, which is unexpected if miR-214 supposedly mediates antiproliferation. Future studies should elucidate this interaction. Further confusion arises from contrasting findings of miR-214 underexpression in cervical cancers [26], but overexpression in cervical invasive squamous cell carcinomas (ISCCs) [142]. However, this could be due to tissue-specific physiological differences. The effect of high-risk HPV subtypes on miR-214 in cervical cancer requires further study, as HPV-16 can downregulate the potentially protective miR-218 [138]. Several other studies have reported miR-214 to suppress cervical tumour growth and metastasis through targeting and downregulating high mobility group AT-hook 1 (HMGA1) [68], Plexin-B1 [72], Bc1212 [62], Ezh2 [63], and forkhead box protein M1 (FOXM1) [66]. The tumour suppressive activities through a vast diversity of targets solidifies miR-214 to be an attractive therapy for cervical cancers.

\subsection{Skin Cancer}

An analysis of malignant melanoma trends, the most lethal skin cancer, has found that mortality has continuously increased over a 30-year period from 1985 [143]. Therefore, new interventions for melanoma treatment are necessary. Exposure to DNA-damaging ultraviolet radiation remains the biggest contributor to melanoma by transforming melanocytes to proliferating malignant cells [144]. Ultraviolet radiation can induce genetic mutations, impair tumour suppressors like p53, or dysregulate pathways such as MAPK. Immune checkpoint inhibitors and kinase inhibitors like trametinib are the primary means of melanoma therapy, however modulating miRNAs may prove clinically relevant.

An early experiment demonstrated differential miRNA expression in melanoma samples [145]. However, these were not compared to healthy samples, so these findings are difficult to interpret. Later, Mueller and colleagues [146] analysed microarrays from melanoma cell lines and found 49 strongly upregulated miRNAs during early melanoma progression. This indicates an association between miRNAs and the transformation to malignancy.

MiR-214 was highly expressed in melanoma cells [24], which is in agreement with previous findings $[147,148]$. In this study, transfection with pre-miR-214 increased cell invasion in vitro [24]. Furthermore, in vivo injection of overexpressing-miR-214 melanoma cells into mice tails increased lung metastases. Luciferase and expression assays in human melanoma samples confirmed that miR-214 targets the adhesion molecule integrin $\alpha 3$ (ITGA3) and transcription factor AP-2 gamma (TFAP2C). However, these findings were limited by the human data set only presenting $\mathrm{mRNA}$, so verification of protein expression is required. Silencing TFAP2C or ITGA3 both increased in vitro cell migration, mirroring the action of miR-214. The protumourigenic effects of miR-214 are likely primarily through downregulating TFAP2C, as it regulates many factors. For example, TFAP2C represses progrowth VEGFA but activates ERBB2 [24]. Unexpectedly, ITGA3 promotes tumour growth in breast cancer, yet the oncogenic miR-214 downregulates it in melanoma [149]. Further study of ITGA3 is needed, but discrepancies may be attributed to unique cellular contexts and tumour microenvironments. Focusing on human cell lines and in vivo tumour samples will help guide melanoma therapy. Moreover, the many factors regulated by TFAP2C require their effects on carcinogenesis to be clarified. For instance, miR-214 upregulates the activated leukocyte cell adhesion molecule (ALCAM) through negatively modulating TFAP2 and miR-148b [150]. Consequently, ALCAM promoted malignant melanoma progression. Orso and colleagues found that inhibiting miR-214 or overexpressing miR-148b can impair melanoma metastasis, due to downregulated ALCAM and ITGA5 adhesion molecules [38]; both of which are direct targets of miR-148b. Furthermore, simultaneously downregulating miR-214 and upregulating miR-148b blocked metastasis in melanoma and breast cancer cells, which presents a promising combinatorial therapy. Overall, the research supports miR-214 to promote melanoma progression and metastasis. 


\subsection{Lung Cancer}

Worldwide, lung cancer causes the most cancer deaths with an estimated 1.7 million deaths in 2018, or $18.4 \%$ of all cancer deaths [125]. Aside from lifestyle changes and tobacco regulation, knowledge of lung carcinogenesis mechanisms can give insight for novel therapies. Current treatments include EGFR-tyrosine kinase inhibitors (EGFR-TKI), such as gefitinib or erlotinib [151,152]. Randomised phase 3 clinical trials have demonstrated that these EGFR-TKIs significantly prolonged survival in patients with activating EGFR mutations, and this was superior to standard chemotherapy protocols. Unfortunately, patients can acquire resistance to EGFR-TKIs.

Microarray comparisons of primary lung cancer samples with healthy tissues revealed 43 differentially expressed miRNAs, with miR-214 being significantly upregulated $\left(p=8.6 \times 10^{-6}\right)$ [153]. MiR-214 was also upregulated in non-small cell lung cancer (NSCLC), which accounts for over $80 \%$ of lung cancer cases [74]. MiR-214 has been implicated in promoting cisplatin resistance in ovarian cancer [23] or reversing resistance in gastric cancer [130]. Additionally, miR-214 can indirectly affect EGFR signalling by targeting JNK1 [26]. Therefore, modulation of gefitinib resistance by miR-214 is plausible.

MiR-214 expression was significantly upregulated in the gefitinib-resistant lung cancer cell line HCC827, from observations of RT-PCR and Northern blotting [25]. Here, knockdown of miR-214 increased PTEN expression and decreased phosphorylation of the protumourigenic Akt pathway. Furthermore, miR-214 knockdown saw previously resistant EGFR-mutant lung cancer cells now sensitive to gefitinib, as shown in MTS viability assays. MiR-214 was confirmed to target PTEN, which supports similar conclusions from other studies [15,22,23,73]. Additional effects of miR-214 targeting PTEN include promoting glycolysis in NSCLC to generate energy for proliferating cancer cells [74]. As miR-214 may confer gefitinib resistance in lung cancer cells, downregulating miR-214 could counter EGFR-TKI resistance [25]. More recently, antagomir-214 was found to reverse NSCLC gefitinib resistance in vitro and in vivo [154]. Further in vivo studies of human cancer samples could verify this, alongside comparisons with non-mutated EGFR cells.

Interestingly, downregulating HDGF with monoclonal antibodies impaired lung cancer growth and vascularity [155]. Likewise, Shih and colleagues [67] found that miR-214 targeted HDGF in HCC, so miR-214 confers drug resistance in lung cancers but could theoretically target HDGF to hinder tumourigenesis. The balance between the oncogenic and tumour suppressive effects of miR-214 in lung cancer is important to explore. Another factor characterised in lung cancer is Twist1, the previously described upregulator of miR-214 in ovarian cancer [50]. Here, Twist1 again increases miR-214 expression which promotes the transition of epithelial cells into migratory mesenchymal cells, thus stimulating metastasis in lung adenocarcinoma [156].

\subsection{Breast Cancer}

Breast cancer is the leading cause of cancer death in women [125]. In 2018, breast cancer was responsible for $6.6 \%$ of all cancer deaths, and nearly one in four cancer diagnoses in women. Inherited BRCA1/2 mutations are prevalent risk factors, as well as hormonal changes from oral contraceptives. Additionally, there is less pressure for early childbearing in developed countries, which increases risk. The high mortality of breast cancer demonstrates an urgent need to find effective treatments.

Analysis of patient blood serum using TaqMan assays and RT-PCR found that miR214 could distinguish between benign and malignant breast cancers [40]. Here, miR-214 concentrations were higher in breast cancer patients compared to healthy women, and miR214 was significantly reduced after surgery. This highlights applications for miR-214 as a diagnostic biomarker to identify breast malignancy. Interestingly, another group observed the downregulation of miR-214 and PTEN in breast cancer tissues [157]. This contradiction is likely due to differences between blood and tumour tissues. Nevertheless, other studies have reported decreased miR-214 expression in breast cancer. Derfoul and colleagues [34] demonstrated an inverse relationship between miR-214 and pro-proliferative Ezh2 expres- 
sion in a breast cancer cell line. The study noted an in vitro inhibition of proliferation and cell invasion upon expression of miR-214. Targeting of Ezh2 is also consistent with studies on cardiac hypertrophy [37]. Extensive research has shown miR-214 to inhibit breast cancer proliferation and increase apoptosis in vitro by targeting survivin [86] and $\beta$-catenin [60], and miR-214 also negatively correlated with the tumour proliferation marker Ki-67 [158]. The latter two studies reported miR-214 downregulation in breast cancer tissues, thus supporting Derfoul and colleagues [34]. However, these groups used the MCF-7 breast cancer cell line, therefore limiting the findings to one environment. Additionally, miR-214 can sensitise breast cancer cells to chemotherapy drugs such as doxorubicin and tamoxifen through directly targeting RFWD2 [79] and UCP2 [88], respectively. Finally, miR-214 targets RNF8, a promoter of metastatic epithelial-mesenchymal transition (EMT) [80]. Importantly, low miR-214 and high RNF8 expression was associated with poor survival in breast cancer patients. In contrast, miR-214-mediated RNF8 targeting encourages ovarian tumourigenesis [81]. Taken together, these studies support miR-214 to suppress breast tumourigenesis through inhibiting proliferation and metastasis, countering chemoresistance, and promoting apoptosis. Further studies should expand on different human cell lines and in vivo models. Screening for further miR-214 targets will also elucidate novel mechanisms.

Despite the extensive research on miR-214 in breast cancer, the field remains polarised. It was reported that high miR-214 expression correlates with poor survival in triple-negative breast cancer (TNBC) patients who lack oestrogen, progesterone and human EGFR receptors [159]. Wang and colleagues observed upregulated miR-214 in breast cancer cell lines alongside increased cell growth and protection against apoptosis through PTEN targeting [35]. This contradicts studies that demonstrated miR-214 downregulation, inhibited proliferation, and increased apoptosis $[34,60,86,158]$. However, their findings are more representative as miR-214 upregulation was observed in four breast cancer cell lines, and not just MCF-7 [35]. Recently, in vitro and in vivo knockdown of miR-214 with R97/R98 compounds inhibited metastasis and extravasation in TNBC and malignant melanoma [160]. However, this study would have benefited from cell-specific miR-214 knockdown, as systemic silencing may cause unintended effects. Nonetheless, these findings agreed with reports of miR-214 promoting breast cancer cell invasion, partly through targeting p53 [71] or $\alpha 1$-antitrypsin ( $\alpha 1-\mathrm{AT})$ [57]. As previously described in melanoma, breast cancer cell metastasis was hindered by inhibiting miR-214 or upregulating miR-148b which targets ALCAM and ITGA5 adhesion molecules [38]. Similarly, through targeting the ST6GAL1 enzyme, miR-214 promoted TNBC cell viability, invasion, and the expression of EMT-related proteins like MMPs and N-cadherin [83]. This is contrary to the study by Min and colleagues [80] who proposed that miR-214 inhibited EMT. However, these contradictions may be due to physiological differences between the aggressive TNBC, which makes up 10-20\% of cases [83], and other types of breast cancer. Altogether, many studies have shown miR-214 to promote breast cancer metastasis and viability, thus establishing miR-214 inhibition as a possible therapeutic route. Further gain-of-function and loss-of-function studies are needed to clarify the conditions where miR-214 acts as an oncogene or as a tumour suppressor in breast cancer. These inconsistencies may be due to the vast diversity of miR-214 targets and the complex nature of cancer cells. Focusing on a broad range of human breast cancer cell lines and appropriate animal models will help gather insight.

\section{MicroRNA-214 in Bone Formation}

Bone formation, or osteogenesis, is balanced by osteoclasts and osteoblasts [161]. Osteoclasts enable bone resorption, whereas osteoblasts facilitate bone formation. The crosstalk between these two cells, combined with other cytokines and signalling pathways like OPG/RANKL/RANK, ultimately regulate bone homeostasis. Without proper function of these cells, osteoporosis can arise from dysfunctional bone remodelling. The role of miR-214 in regulating bone formation is summarised in Figure 6 and discussed in more detail below. 


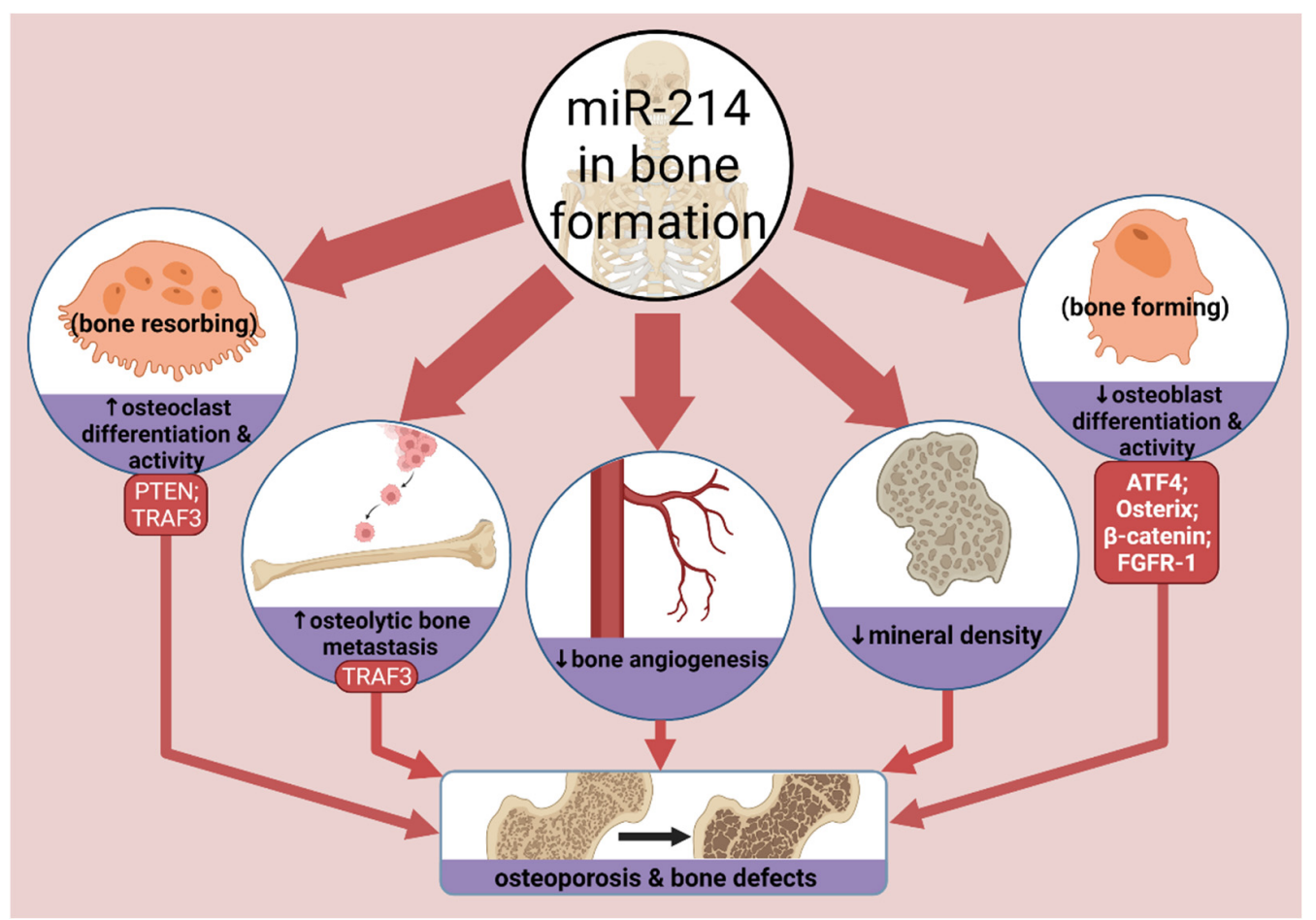

Figure 6. Effects of miR-214 on bone formation. Summary of the detrimental effects of miR-214 on bone formation, with known target mRNA/proteins indicated, as discussed in the main text. Some effects only apply to specific cells or experimental conditions. See the main text of Section 5 for detailed information and references. Created with BioRender.com.

\subsection{Osteoblasts}

Early microarray analyses found 22 downregulated miRNAs during osteogenesis [162]. However, the scarcity of in vivo studies and the vast number of miRNAs means little is known about their individual function. Nevertheless, miR-125b [163] and miR-2861 [164] can inhibit and promote osteoblast differentiation, respectively. In one of the first studies to characterise a role for miR-214 in osteogenesis, Wang and colleagues detected miR214 correlating with poor expression of bone formation markers, such as osteocalcin, in humans, [30]. Luciferase reporters identified the pro-osteogenic activating transcription factor 4 (ATF4) as a direct miR-214 target. Similarly, Li and colleagues found exosomal miR-214 to impair osteogenesis in vitro and in vivo [55].

Supporting the study of Wang [30], another study found miR-214 to target ATF4 and impair the differentiation of human periodontal ligament stem cells (hPDLSCs) to osteoblasts [58]. This could be hPDLSC-specific, but miR-214 can also inhibit osteogenic differentiation in mesenchymal stem cells (MSC) through targeting FGFR-1 [65], and $\beta$-catenin [61]. Additionally, Shi and colleagues found that miR-214 targeted osterix (Osx) [70]; a transcription factor required for osteoblast differentiation. Mice lacking Osx die shortly after birth. The study found that inhibiting miR-214 in the $\mathrm{C} 2 \mathrm{C} 12$ myoblast cell line resulted in increased osteogenic markers, including alkaline phosphatase (ALP), Col1 $\alpha 1$ and osteocalcin. Interestingly, XBP1 upregulates Osx transcription [165]. In combination with findings that miR-214 targets XBP1 [16], studies should explore the interactions between miR-214 and XBP1-Osx activity.

Taken altogether, these findings suggest that the therapeutic inhibition of miR-214 can restore bone formation and improve osteoblast activity and differentiation. According to the aptly named Bonewald, $W n t / \beta$-catenin signalling is also implicated in osteocytes [166]. This warrants further study as miR-214 is known to target $\beta$-catenin [59,61], so miR-214 may affect $W n t / \beta$-catenin during osteogenesis. 


\subsection{Osteoclasts}

Conversely, miR-214 can promote osteoclast differentiation [75]. Osteoclast-specific miR-214 downregulated PTEN and upregulated osteoclast activity and differentiation markers in vivo. In addition, miR-214 promoted excessive osteoclastic resorption in vitro through targeting TRAF3, which encouraged osteolytic bone metastasis (OBM) in breast cancer patients [87]. Antagonising miR-214 could therefore reduce OBM, osteoclastogenesis and bone-resorption, thus encouraging osteoblastic bone formation. Interestingly, miR-214 decreased after exercise and knee-loading in mice, thus increasing mineral density and bone angiogenesis $[167,168]$. This suggests that exercise prevents osteoporosis through inhibiting miR-214, although this requires further testing.

\subsection{Therapeutics}

Targeting miR-214 with baculovirus gene therapy to treat osteoporosis is promising. A baculovirus vector was engineered to express an miR-214 'sponge' to bind miR-214 and negate its activity $[39,169]$. This rescued Wnt/ $\beta$-catenin signalling promoted osteoblast activity and healed osteoporotic defects in ovariectomised (OVX) rats. The lncRNA MALAT1 also sponges miR-214 and can improve osteogenesis by preventing ATF4 downregulation [46]. Similarly, miR-214 sponging was seen with the lncRNA XIST [47], and the pseudogene PTENP1 [170]. Additionally, delivering cell-specific anti-miR-214 in polyurethane nanomicelle vectors to osteoclasts in OVX mice saw low toxicity and improved bone formation [171]. This is a potential alternative to the dangerous side effects from bisphosphonates used for treating osteoporosis. However, it is important not to overuse anti-miR-214 therapy. Li and colleagues showed that calcific aortic valve disease (CAVD), caused by excessive osteogenesis, can be alleviated by miR-214 which inhibits osteogenic differentiation of valvular interstitial cells [172]. Therefore, miR-214 is protective when moderately antiosteogenic, as it normalises overbearing bone formation.

\section{MicroRNA-214 in Cell Differentiation}

The effects of miR-214 on the differentiation of muscle cells, neuronal cells and T-cells is summarised in Figure 7 and discussed in detail below.

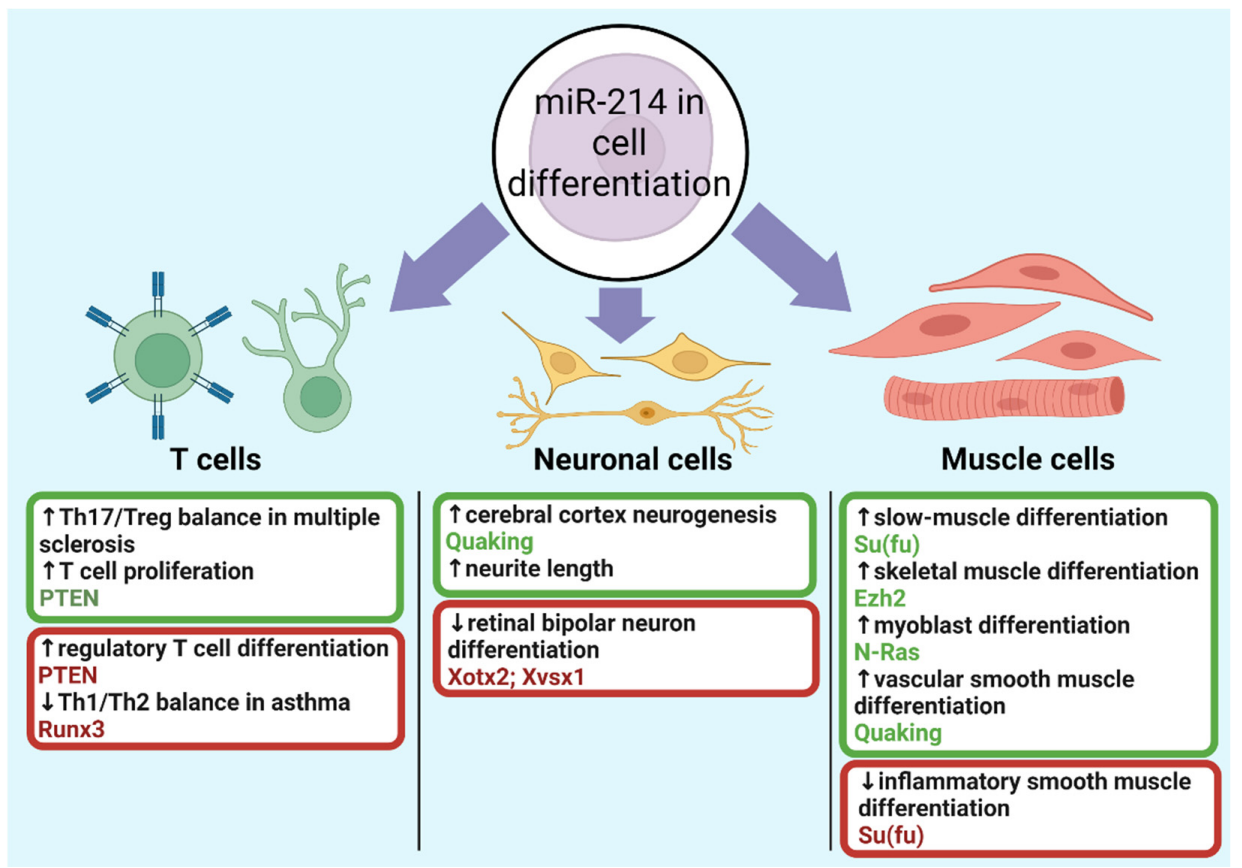

Figure 7. Effects of miR-214 on cell differentiation. Broad summary of the protective (green) and detrimental (red) effects of miR-214 on cell differentiation, with known target mRNA/proteins 
indicated, as discussed within this review. Some effects only apply to specific cells or experimental conditions. See Section 6 for detailed information and references. Created with BioRender.com.

\subsection{Muscle Cells}

Skeletal muscles develop through myogenesis, where precursors differentiate into myoblasts and eventually myofibres [173]. Myogenesis is controlled through various signalling pathways and transcription factors, although miRNAs are appearing to be increasingly involved. DICER knockouts diminish miRNA processing and cause embryonic lethality in mice due to skeletal muscle hypoplasia [174]. Therefore, understanding miRNAs in myogenesis is important for treating skeletal muscle defects.

Initially, miR-214 was reported to regulate muscle cell development in zebrafish [84]. Here, miR-214 expression was high early in embryonic development, and by targeting $\mathrm{Su}(\mathrm{fu})$, hedgehog signalling is activated. Moreover, inhibiting miR-214 reduced differentiation for slow-muscle cell types. Porcine skeletal muscle tissues also revealed differential miR-214 expression between foetal and adult samples [175]. Furthermore, disruption of the Dnm3os gene, which encodes the miR-214/miR-199a cluster, caused skeletal defects and postnatal death in mice [49]. These findings suggest a critical role for miR-214 in myogenesis and cell maturation.

Ezh2, the catalytic subunit of the polycomb repressive complex 2 (PRC2), establishes a feedback loop with miR-214 during skeletal muscle cell (SMC) differentiation [31]. PcG proteins suppress miR-214 transcription, but these proteins are released during SMC differentiation. Subsequently, miR-214 downregulates Ezh2 translation which impairs PcG proteins and facilitates further miR-214 transcription, overall, accelerating SMC differentiation. Additionally, C2C12 myoblast differentiation was attenuated upon anti-miR-214 transfection [56]. In agreement, Liu and colleagues described miR-214 to promote C2C12 mouse myoblast differentiation by targeting N-Ras [69]. Altogether, miR-214 can positively regulate muscle cell differentiation. However, these experiments were in vitro and nonhuman specific, so studying in vitro and in vivo human models is needed before considering miR-214 in clinical settings. Contrary to expectations, miR-214 was also downregulated in differentiating C2C12 myoblasts [176]. A plausible explanation is that unsuppressed miR-214 targets promote myogenesis, such as Akt. Future studies should examine the interplay between targets and how their effects outbalance each other.

Overexpressing miR-214 also promotes embryonic stem cell (ESC) differentiation to vascular smooth muscle cells (VSMCs) both in vitro and in vivo by targeting Quaking [32]. Quaking suppresses the promoter regions of transcription factors involved in VSMC development such as MEF2c, so miR-214 releases their inhibition. This cannot be generalised to all SMC, however, as He and colleagues found miR-214 to inhibit the differentiation to inflammatory SMC by targeting Su(fu) [85]. Additionally, the contrasting effects of miR-214 targets are observed, as miR-214 promotes muscle cell differentiation in zebrafish by also targeting $\mathrm{Su}(\mathrm{fu})$ [84]. These differences likely depend on cellular contexts and other transcriptional factors.

\subsection{Neuronal Cells}

Other instances of miR-214 modulating cell differentiation have been realised in neuronal cells. The inhibition of Xotx 2 and Xvsx1 mRNAs by miR-214 prevents retinal progenitor cells from differentiating into bipolar neurons in Xenopus [90]. In contrast, another study found miR-214 to be upregulated and increased neurite length in differentiated neuroblastoma cells [177]. Additionally, miR-214 targeted Quaking to promote neurogenesis, the generation of new neurons, during cerebral cortex development [78]. However, miR-214 was also downregulated in differentiated neurons, suggesting an anti-differentiation effect [178]. Surprisingly, inhibiting miR-214 here did not promote neurogenesis, indicating other mechanisms which merit future investigation. 


\section{3. $T$ Cells}

Immunomodulatory roles of miR-214 are becoming apparent with $\mathrm{T}$ cells. Through targeting PTEN, tumour-secreted miR-214 can promote CD4+ T cell differentiation into regulatory T cells (Tregs) [33]. Tregs inhibit cell-mediated immunity carried out by CD4+ and CD8+ T cells, thus enabling tumours to evade immunity. However, this study showed that anti-miR-214 delivery in microvesicles prevents Treg expansion in vivo, which supports miRNA-based therapy to attenuate tumour growth. Furthermore, CD28 costimulation can upregulate miR-214 to increase T cell proliferation by downregulating PTEN, a negative modulator of $\mathrm{T}$ cell signalling [76].

Multiple sclerosis (MS) is facilitated by Th17/Treg cell imbalances, which encourage aggressively pathogenic Th17 cells [179]. MiR-214 promotes Treg differentiation here by inhibiting mTOR signalling, therefore balancing Th17/Treg populations. Interestingly, these effects were opposite to miR-27a, which indicates antagonistic interactions with other miRNAs. Similarly, the Runx3 transcription factor can help restore the Th1/Th2 cell balance in asthmatic patients [82]. Runx3 is targeted by five miRNAs, including miR-214. The balance was only restored upon inhibition of all five miRNAs, implying overlapping functions which allow miRNAs to compensate for each other. Overall, studying miR-214 in cell differentiation aids the understanding of regenerative medicine. Viewed alongside osteogenesis studies, it appears miR-214 preferentially promotes the differentiation of specific cells, such as muscle cells [31], and inhibits others, such as osteoblasts [58].

\section{Conclusions and Future Perspectives}

The discovery of miRNAs, in 1993, revolutionised the field of ncRNAs, and studies have since been undertaken to elucidate the regulatory functions of miRNAs in numerous health conditions. This review has described the diverse and complex roles of miR-214 as an oncogene, tumour suppressor, protector against $\mathrm{Ca}^{2+}$ overload and oxidative damage, mediator of angiogenesis and pathological fibrosis, and as a regulator in osteogenesis, myogenesis and cellular immunity. Through a vast repertoire of targets, miR-214 influences multiple cellular functions. Oftentimes, contrasting roles are attributed to particular targets. Screening for further miR-214 targets is therefore paramount, as it could reveal a myriad of novel functions in seemingly unrelated diseases. Future studies should also explore external regulators, such as Twist1, as it unlocks possibilities for therapeutic miR-214 modulation. Moreover, miR-214 uptake and secretion are not well understood, which is particularly relevant in tumour microenvironments. Finally, polarised areas remain in the literature, such as in cardiac fibrosis, but more so in breast cancer where contradictions occur even in the same cell lines [34,35]. Further in vivo and in vitro experiments are required to define what dictates miR-214 to act as a tumour suppressor or promoter.

It is important to consider different models, as unique cellular environments yield varying results. In vitro observations may be inconsistent with in vivo animal models, in addition to the disparities between different species. Furthermore, transfecting premiR-214 and anti-miR-214 into specific cells is not the same as direct genetic deletions or transgenic animals overexpressing miRNAs systemically. Apart from experimental conditions, opposing interactions between miRNAs and their targets must also be considered, such as miR-148b and miR-199a [38]. Additionally, the less-studied miR-214* requires further investigation. A comprehensive view of miR-214 and the miRNA interactome in human health should be acquired through studying in vitro human cell types, and in vivo cell-specific models using a combination of analytical methods.

Clinical therapies targeting miRNAs are beginning to become a reality. Indeed, a number of pharmaceutical companies have miRNA-based therapeutics in their pipelines with varying success. For example, Roche acquired the miR-122 antagomir, Miravirsen (SPC3649), which is in multiple phase 2 clinical trials for the treatment of hepatitis $C$ virus (HCV) and is a modified locked nucleic acid (LNA) and acts by preventing miR-122 binding to the 5' UTR HCV genome and ultimately reduces genome transcription [180]. Similarly, Regulus Therapeutics, a company whose pipeline consists purely of miRNA-based ther- 
apeutics, has an anti-miRNA oligonucleotide (RG-012) which has been awarded orphan drug status by the FDA for the target of miR-21 to prevent the translation of polysomes in kidney dysfunction for the treatment of patients with Alport syndrome [181]. A third company, miRagen Therapeutics, recently reported the results from a phase 2 clinical trial investigating the safety and tolerability of Remlarsen (MRG-201), a miR-29 miRNA-mimic for the treatment of fibrosis and patients with a history of keloid scars. The specific miR-29 activity being mimicked in this potential treatment is the reduction in collagen expression as well as other proteins involved in fibrosis [182]. These miRNA-based therapeutics utilise the ability to both inhibit and mimic the activity of miRNAs and reflect the important role miRNAs play in the regulation of human disease. It remains to be seen whether therapies aimed specifically at miR-214 will be developed in the future.

MiR-214 can also act as a diagnostic marker for identifying severe diseases like CAD [41], and this should be explored with other diseases. Many studies also indicate that overexpressing or silencing miR-214 can relieve cardiovascular injury and carcinogenesis both in vitro and in vivo. Recent studies show promise in sponging miR-214 with lncRNAs [46,47] or using cell-specific delivery to relieve osteoporosis [171], although preventing toxicity and ensuring accurate delivery is challenging.

The diversity of miR-214 action is amplified through the variety of targets shown in Table 1, many of which have multiple downstream functions, alongside combinatorial interactions with other targets and miRNAs. Consequently, the therapeutic manipulation of miR-214 must be practised in specific physiological domains to avoid unintended consequences. Care must also be taken to neither negate nor promote the beneficial and detrimental effects of miR-214, respectively. The pleiotropic nature of miR-214 therefore demands a fine balance, for example, in allowing moderate inhibition of osteogenesis to prevent CAVD [172]. Understanding this enigmatic balance through functional studies is a long-term goal for future research in this area.

Author Contributions: Conceptualization, M.M.J.A. and N.A.T.; writing—original draft preparation, M.M.J.A.; writing—review and editing, M.M.J.A., C.J.T. and N.A.T.; funding acquisition, N.A.T. All authors have read and agreed to the published version of the manuscript.

Funding: This research was funded by The British Heart Foundation, grant number FS/19/41/34478.

Institutional Review Board Statement: Not applicable.

Informed Consent Statement: Not applicable.

Data Availability Statement: Not applicable.

Acknowledgments: All figures were produced using Biorender software at Biorender.com.

Conflicts of Interest: The authors declare no conflict of interest. The funders had no role in the writing of the manuscript.

\section{References}

1. Consortium, E.P. An integrated encyclopedia of DNA elements in the human genome. Nature 2012, 489, 57-74. [CrossRef]

2. Beermann, J.; Piccoli, M.T.; Viereck, J.; Thum, T. Non-coding RNAs in Development and Disease: Background, Mechanisms, and Therapeutic Approaches. Physiol. Rev. 2016, 96, 1297-1325. [CrossRef] [PubMed]

3. O'Brien, J.; Hayder, H.; Zayed, Y.; Peng, C. Overview of MicroRNA Biogenesis, Mechanisms of Actions, and Circulation. Front. Endocrinol. 2018, 9, 402. [CrossRef]

4. Lee, R.C.; Feinbaum, R.L.; Ambros, V. The C. elegans heterochronic gene lin-4 encodes small RNAs with antisense complementarity to lin-14. Cell 1993, 75, 843-854. [CrossRef]

5. Alles, J.; Fehlmann, T.; Fischer, U.; Backes, C.; Galata, V.; Minet, M.; Hart, M.; Abu-Halima, M.; Grässer, F.A.; Lenhof, H.P.; et al. An estimate of the total number of true human miRNAs. Nucleic Acids Res. 2019, 47, 3353-3364. [CrossRef] [PubMed]

6. Kozomara, A.; Birgaoanu, M.; Griffiths-Jones, S. miRBase: From microRNA sequences to function. Nucleic Acids Res. 2019, 47, D155-d162. [CrossRef] [PubMed]

7. Baek, D.; Villén, J.; Shin, C.; Camargo, F.D.; Gygi, S.P.; Bartel, D.P. The impact of microRNAs on protein output. Nature 2008, 455, 64-71. [CrossRef] [PubMed]

8. Tang, F.; Kaneda, M.; O'Carroll, D.; Hajkova, P.; Barton, S.C.; Sun, Y.A.; Lee, C.; Tarakhovsky, A.; Lao, K.; Surani, M.A. Maternal microRNAs are essential for mouse zygotic development. Genes Dev. 2007, 21, 644-648. [CrossRef] 
9. Bernstein, E.; Kim, S.Y.; Carmell, M.A.; Murchison, E.P.; Alcorn, H.; Li, M.Z.; Mills, A.A.; Elledge, S.J.; Anderson, K.V.; Hannon, G.J. Dicer is essential for mouse development. Nat. Genet. 2003, 35, 215-217. [CrossRef] [PubMed]

10. Cheng, A.M.; Byrom, M.W.; Shelton, J.; Ford, L.P. Antisense inhibition of human miRNAs and indications for an involvement of miRNA in cell growth and apoptosis. Nucleic Acids Res. 2005, 33, 1290-1297. [CrossRef]

11. Zhao, Y.; Ponnusamy, M.; Zhang, L.; Zhang, Y.; Liu, C.; Yu, W.; Wang, K.; Li, P. The role of miR-214 in cardiovascular diseases. Eur. J. Pharm. 2017, 816, 138-145. [CrossRef] [PubMed]

12. Penna, E.; Orso, F.; Taverna, D. miR-214 as a key hub that controls cancer networks: Small player, multiple functions. J. Investig. Dermatol. 2015, 135, 960-969. [CrossRef] [PubMed]

13. Sun, Y.; Kuek, V.; Liu, Y.; Tickner, J.; Yuan, Y.; Chen, L.; Zeng, Z.; Shao, M.; He, W.; Xu, J. MiR-214 is an important regulator of the musculoskeletal metabolism and disease. J. Cell. Physiol. 2018, 234, 231-245. [CrossRef]

14. Aurora, A.B.; Mahmoud, A.I.; Luo, X.; Johnson, B.A.; van Rooij, E.; Matsuzaki, S.; Humphries, K.M.; Hill, J.A.; Bassel-Duby, R.; Sadek, H.A.; et al. MicroRNA-214 protects the mouse heart from ischemic injury by controlling $\mathrm{Ca}^{2+}$ overload and cell death. J. Clin. Investig. 2012, 122, 1222-1232. [CrossRef] [PubMed]

15. Lv, G.; Shao, S.; Dong, H.; Bian, X.; Yang, X.; Dong, S. MicroRNA-214 protects cardiac myocytes against H2O2-induced injury. J. Cell. Biochem. 2014, 115, 93-101. [CrossRef] [PubMed]

16. Duan, Q.; Yang, L.; Gong, W.; Chaugai, S.; Wang, F.; Chen, C.; Wang, P.; Zou, M.H.; Wang, D.W. MicroRNA-214 Is Upregulated in Heart Failure Patients and Suppresses XBP1-Mediated Endothelial Cells Angiogenesis. J. Cell. Physiol. 2015, 230, $1964-1973$. [CrossRef] [PubMed]

17. Sun, M.; Yu, H.; Zhang, Y.; Li, Z.; Gao, W. MicroRNA-214 mediates isoproterenol-induced proliferation and collagen synthesis in cardiac fibroblasts. Sci. Rep. 2015, 5, 18351. [CrossRef] [PubMed]

18. Bageghni, S.A.; Hemmings, K.E.; Zava, N.; Denton, C.P.; Porter, K.E.; Ainscough, J.F.X.; Drinkhill, M.J.; Turner, N.A. Cardiac fibroblast-specific p38 $\alpha$ MAP kinase promotes cardiac hypertrophy via a putative paracrine interleukin-6 signaling mechanism. FASEB J. 2018, 32, 4941-4954. [CrossRef] [PubMed]

19. Zhu, W.S.; Tang, C.M.; Xiao, Z.; Zhu, J.N.; Lin, Q.X.; Fu, Y.H.; Hu, Z.Q.; Zhang, Z.; Yang, M.; Zheng, X.L.; et al. Targeting EZH1 and EZH2 contributes to the suppression of fibrosis-associated genes by miR-214-3p in cardiac myofibroblasts. Oncotarget 2016, 7, 78331-78342. [CrossRef] [PubMed]

20. Dong, H.; Dong, S.; Zhang, L.; Gao, X.; Lv, G.; Chen, W.; Shao, S. MicroRNA-214 exerts a Cardio-protective effect by inhibition of fibrosis. Anat. Rec. (Hoboken N. J. 2007) 2016, 299, 1348-1357. [CrossRef] [PubMed]

21. Yang, K.; Shi, J.; Hu, Z.; Hu, X. The deficiency of miR-214-3p exacerbates cardiac fibrosis via miR-214-3p/NLRC5 axis. Clin. Sci. (Lond. Engl. 1979) 2019, 133, 1845-1856. [CrossRef]

22. Yang, T.S.; Yang, X.H.; Wang, X.D.; Wang, Y.L.; Zhou, B.; Song, Z.S. MiR-214 regulate gastric cancer cell proliferation, migration and invasion by targeting PTEN. Cancer Cell Int. 2013, 13, 68. [CrossRef]

23. Yang, H.; Kong, W.; He, L.; Zhao, J.J.; O’Donnell, J.D.; Wang, J.; Wenham, R.M.; Coppola, D.; Kruk, P.A.; Nicosia, S.V.; et al. MicroRNA expression profiling in human ovarian cancer: miR-214 induces cell survival and cisplatin resistance by targeting PTEN. Cancer Res. 2008, 68, 425-433. [CrossRef]

24. Penna, E.; Orso, F.; Cimino, D.; Tenaglia, E.; Lembo, A.; Quaglino, E.; Poliseno, L.; Haimovic, A.; Osella-Abate, S.; De Pittà, C.; et al. microRNA-214 contributes to melanoma tumour progression through suppression of TFAP2C. EMBO J. 2011, 30, 1990-2007. [CrossRef]

25. Wang, Y.S.; Wang, Y.H.; Xia, H.P.; Zhou, S.W.; Schmid-Bindert, G.; Zhou, C.C. MicroRNA-214 regulates the acquired resistance to gefitinib via the PTEN/AKT pathway in EGFR-mutant cell lines. Asian Pac. J. Cancer Prev. 2012, 13, 255-260. [CrossRef]

26. Yang, Z.; Chen, S.; Luan, X.; Li, Y.; Liu, M.; Li, X.; Liu, T.; Tang, H. MicroRNA-214 is aberrantly expressed in cervical cancers and inhibits the growth of HeLa cells. IUBMB Life 2009, 61, 1075-1082. [CrossRef]

27. Zhang, X.J.; Ye, H.; Zeng, C.W.; He, B.; Zhang, H.; Chen, Y.Q. Dysregulation of miR-15a and miR-214 in human pancreatic cancer. J. Hematol. Oncol. 2010, 3, 46. [CrossRef]

28. Misiewicz-Krzeminska, I.; Sarasquete, M.E.; Quwaider, D.; Krzeminski, P.; Ticona, F.V.; Paíno, T.; Delgado, M.; Aires, A.; Ocio, E.M.; García-Sanz, R.; et al. Restoration of microRNA-214 expression reduces growth of myeloma cells through positive regulation of P53 and inhibition of DNA replication. Haematologica 2013, 98, 640-648. [CrossRef]

29. Deng, M.; Ye, Q.; Qin, Z.; Zheng, Y.; He, W.; Tang, H.; Zhou, Y.; Xiong, W.; Zhou, M.; Li, X.; et al. miR-214 promotes tumorigenesis by targeting lactotransferrin in nasopharyngeal carcinoma. Tumour Biol. 2013, 34, 1793-1800. [CrossRef]

30. Wang, X.; Guo, B.; Li, Q.; Peng, J.; Yang, Z.; Wang, A.; Li, D.; Hou, Z.; Lv, K.; Kan, G.; et al. miR-214 targets ATF4 to inhibit bone formation. Nat. Med. 2013, 19, 93-100. [CrossRef]

31. Juan, A.H.; Kumar, R.M.; Marx, J.G.; Young, R.A.; Sartorelli, V. Mir-214-dependent regulation of the polycomb protein Ezh2 in skeletal muscle and embryonic stem cells. Mol. Cell 2009, 36, 61-74. [CrossRef]

32. Wu, Y.; Li, Z.; Yang, M.; Dai, B.; Hu, F.; Yang, F.; Zhu, J.; Chen, T.; Zhang, L. MicroRNA-214 regulates smooth muscle cell differentiation from stem cells by targeting RNA-binding protein QKI. Oncotarget 2017, 8, 19866-19878. [CrossRef]

33. Yin, Y.; Cai, X.; Chen, X.; Liang, H.; Zhang, Y.; Li, J.; Wang, Z.; Chen, X.; Zhang, W.; Yokoyama, S.; et al. Tumor-secreted miR-214 induces regulatory T cells: A major link between immune evasion and tumor growth. Cell Res. 2014, 24, 1164-1180. [CrossRef] 
34. Derfoul, A.; Juan, A.H.; Difilippantonio, M.J.; Palanisamy, N.; Ried, T.; Sartorelli, V. Decreased microRNA-214 levels in breast cancer cells coincides with increased cell proliferation, invasion and accumulation of the Polycomb Ezh2 methyltransferase. Carcinogenesis 2011, 32, 1607-1614. [CrossRef]

35. Wang, F.; Li, L.; Chen, Z.; Zhu, M.; Gu, Y. MicroRNA-214 acts as a potential oncogene in breast cancer by targeting the PTEN-PI3K/Akt signaling pathway. Int. J. Mol. Med. 2016, 37, 1421-1428. [CrossRef]

36. Dangwal, S.; Bang, C.; Thum, T. Novel techniques and targets in cardiovascular microRNA research. Cardiovasc. Res. 2012, 93, 545-554. [CrossRef]

37. Yang, T.; Gu, H.; Chen, X.; Fu, S.; Wang, C.; Xu, H.; Feng, Q.; Ni, Y. Cardiac hypertrophy and dysfunction induced by overexpression of miR-214 in vivo. J. Surg. Res 2014, 192, 317-325. [CrossRef]

38. Orso, F.; Quirico, L.; Virga, F.; Penna, E.; Dettori, D.; Cimino, D.; Coppo, R.; Grassi, E.; Elia, A.R.; Brusa, D.; et al. miR-214 and miR-148b Targeting Inhibits Dissemination of Melanoma and Breast Cancer. Cancer Res. 2016, 76, 5151-5162. [CrossRef]

39. Li, K.C.; Chang, Y.H.; Yeh, C.L.; Hu, Y.C. Healing of osteoporotic bone defects by baculovirus-engineered bone marrow-derived MSCs expressing MicroRNA sponges. Biomaterials 2016, 74, 155-166. [CrossRef]

40. Schwarzenbach, H.; Milde-Langosch, K.; Steinbach, B.; Müller, V.; Pantel, K. Diagnostic potential of PTEN-targeting miR-214 in the blood of breast cancer patients. Breast Cancer Res. Treat. 2012, 134, 933-941. [CrossRef]

41. Lu, H.Q.; Liang, C.; He, Z.Q.; Fan, M.; Wu, Z.G. Circulating miR-214 is associated with the severity of coronary artery disease. J. Geriatr. Cardiol. 2013, 10, 34-38.

42. Ruby, J.G.; Jan, C.H.; Bartel, D.P. Intronic microRNA precursors that bypass Drosha processing. Nature 2007, 448, 83-86. [CrossRef]

43. Yang, J.S.; Maurin, T.; Robine, N.; Rasmussen, K.D.; Jeffrey, K.L.; Chandwani, R.; Papapetrou, E.P.; Sadelain, M.; O'Carroll, D.; Lai, E.C. Conserved vertebrate mir-451 provides a platform for Dicer-independent, Ago2-mediated microRNA biogenesis. Proc. Natl. Acad. Sci. USA 2010, 107, 15163-15168. [CrossRef]

44. Lee, I.; Ajay, S.S.; Yook, J.I.; Kim, H.S.; Hong, S.H.; Kim, N.H.; Dhanasekaran, S.M.; Chinnaiyan, A.M.; Athey, B.D. New class of microRNA targets containing simultaneous 5'-UTR and 3'-UTR interaction sites. Genome Res. 2009, 19, 1175-1183. [CrossRef]

45. van Rooij, E. The art of microRNA research. Circ. Res. 2011, 108, 219-234. [CrossRef]

46. Huang, X.Z.; Huang, J.; Li, W.Z.; Wang, J.J.; Song, D.Y.; Ni, J.D. LncRNA-MALAT1 promotes osteogenic differentiation through regulating ATF4 by sponging miR-214: Implication of steroid-induced avascular necrosis of the femoral head. Steroids 2020, 154, 108533. [CrossRef]

47. Feng, Y.; Wan, P.; Yin, L. Long Noncoding RNA X-Inactive Specific Transcript (XIST) Promotes Osteogenic Differentiation of Periodontal Ligament Stem Cells by Sponging MicroRNA-214-3p. Med. Sci. Monit. 2020, 26, e918932. [CrossRef]

48. Loebel, D.A.; Tsoi, B.; Wong, N.; Tam, P.P. A conserved noncoding intronic transcript at the mouse Dnm3 locus. Genomics 2005, 85, 782-789. [CrossRef]

49. Watanabe, T.; Sato, T.; Amano, T.; Kawamura, Y.; Kawamura, N.; Kawaguchi, H.; Yamashita, N.; Kurihara, H.; Nakaoka, T. Dnm3os, a non-coding RNA, is required for normal growth and skeletal development in mice. Dev. Dyn. 2008, 237, 3738-3748. [CrossRef]

50. Yin, G.; Chen, R.; Alvero, A.B.; Fu, H.H.; Holmberg, J.; Glackin, C.; Rutherford, T.; Mor, G. TWISTing stemness, inflammation and proliferation of epithelial ovarian cancer cells through MIR199A2/214. Oncogene 2010, 29, 3545-3553. [CrossRef]

51. Lee, Y.B.; Bantounas, I.; Lee, D.Y.; Phylactou, L.; Caldwell, M.A.; Uney, J.B. Twist-1 regulates the miR-199a/214 cluster during development. Nucleic Acids Res. 2009, 37, 123-128. [CrossRef]

52. Li, H.; Wang, H.; Ren, Z. MicroRNA-214-5p Inhibits the Invasion and Migration of Hepatocellular Carcinoma Cells by Targeting Wiskott-Aldrich Syndrome Like. Cell. Physiol. Biochem. 2018, 46, 757-764. [CrossRef]

53. Cao, T.H.; Ling, X.; Chen, C.; Tang, W.; Hu, D.M.; Yin, G.J. Role of miR-214-5p in the migration and invasion of pancreatic cancer cells. Eur. Rev. Med. Pharmacol. Sci. 2018, 22, 7214-7221.

54. Iizuka, M.; Ogawa, T.; Enomoto, M.; Motoyama, H.; Yoshizato, K.; Ikeda, K.; Kawada, N. Induction of microRNA-214-5p in human and rodent liver fibrosis. Fibrogenesis Tissue Repair 2012, 5, 12. [CrossRef]

55. Li, D.; Liu, J.; Guo, B.; Liang, C.; Dang, L.; Lu, C.; He, X.; Cheung, H.Y.; Xu, L.; Lu, C.; et al. Osteoclast-derived exosomal miR-214-3p inhibits osteoblastic bone formation. Nat. Commun. 2016, 7, 10872. [CrossRef]

56. Feng, Y.; Cao, J.H.; Li, X.Y.; Zhao, S.H. Inhibition of miR-214 expression represses proliferation and differentiation of C2C12 myoblasts. Cell Biochem. Funct. 2011, 29, 378-383. [CrossRef]

57. Zhang, Y.; Zhao, Z.; Li, S.; Dong, L.; Li, Y.; Mao, Y.; Liang, Y.; Tao, Y.; Ma, J. Inhibition of miR-214 attenuates the migration and invasion of triple-negative breast cancer cells. Mol. Med. Rep. 2019, 19, 4035-4042. [CrossRef]

58. Yao, S.; Zhao, W.; Ou, Q.; Liang, L.; Lin, X.; Wang, Y. MicroRNA-214 Suppresses Osteogenic Differentiation of Human Periodontal Ligament Stem Cells by Targeting ATF4. Stem Cells Int. 2017, 2017, 3028647. [CrossRef]

59. Wang, X.; Chen, J.; Li, F.; Lin, Y.; Zhang, X.; Lv, Z.; Jiang, J. MiR-214 inhibits cell growth in hepatocellular carcinoma through suppression of $\beta$-catenin. Biochem. Biophys. Res. Commun. 2012, 428, 525-531. [CrossRef]

60. Yi, S.J.; Li, L.L.; Tu, W.B. MiR-214 negatively regulates proliferation and WNT/ $\beta$-catenin signaling in breast cancer. Eur. Rev. Med. Pharmacol. Sci. 2016, 20, 5148-5154.

61. Li, J.P.; Zhuang, H.T.; Xin, M.Y.; Zhou, Y.L. MiR-214 inhibits human mesenchymal stem cells differentiating into osteoblasts through targeting $\beta$-catenin. Eur. Rev. Med. Pharmacol. Sci. 2017, 21, 4777-4783. 
62. Wang, F.; Liu, M.; Li, X.; Tang, H. MiR-214 reduces cell survival and enhances cisplatin-induced cytotoxicity via down-regulation of Bcl212 in cervical cancer cells. FEBS Lett. 2013, 587, 488-495. [CrossRef]

63. Yang, Y.; Liu, Y.; Li, G.; Li, L.; Geng, P.; Song, H. microRNA-214 suppresses the growth of cervical cancer cells by targeting EZH2. Oncol. Lett. 2018, 16, 5679-5686. [CrossRef]

64. Wang, J.; Li, J.; Wang, X.; Zheng, C.; Ma, W. Downregulation of microRNA-214 and overexpression of FGFR-1 contribute to hepatocellular carcinoma metastasis. Biochem. Biophys. Res. Commun. 2013, 439, 47-53. [CrossRef]

65. Yang, L.; Ge, D.; Cao, X.; Ge, Y.; Chen, H.; Wang, W.; Zhang, H. MiR-214 Attenuates Osteogenic Differentiation of Mesenchymal Stem Cells via Targeting FGFR1. Cell. Physiol. Biochem. 2016, 38, 809-820. [CrossRef]

66. Wang, J.M.; Ju, B.H.; Pan, C.J.; Gu, Y.; Li, M.Q.; Sun, L.; Xu, Y.Y.; Yin, L.R. MiR-214 inhibits cell migration, invasion and promotes the drug sensitivity in human cervical cancer by targeting FOXM1. Am. J. Transl Res. 2017, 9, 3541-3557.

67. Shih, T.C.; Tien, Y.J.; Wen, C.J.; Yeh, T.S.; Yu, M.C.; Huang, C.H.; Lee, Y.S.; Yen, T.C.; Hsieh, S.Y. MicroRNA-214 downregulation contributes to tumor angiogenesis by inducing secretion of the hepatoma-derived growth factor in human hepatoma. J. Hepatol. 2012, 57, 584-591. [CrossRef]

68. Chandrasekaran, K.S.; Sathyanarayanan, A.; Karunagaran, D. MicroRNA-214 suppresses growth, migration and invasion through a novel target, high mobility group AT-hook 1, in human cervical and colorectal cancer cells. Br. J. Cancer 2016, 115, 741-751. [CrossRef]

69. Liu, J.; Luo, X.J.; Xiong, A.W.; Zhang, Z.D.; Yue, S.; Zhu, M.S.; Cheng, S.Y. MicroRNA-214 promotes myogenic differentiation by facilitating exit from mitosis via down-regulation of proto-oncogene N-ras. J. Biol. Chem. 2010, 285, 26599-26607. [CrossRef]

70. Shi, K.; Lu, J.; Zhao, Y.; Wang, L.; Li, J.; Qi, B.; Li, H.; Ma, C. MicroRNA-214 suppresses osteogenic differentiation of C2C12 myoblast cells by targeting Osterix. Bone 2013, 55, 487-494. [CrossRef]

71. Wang, F.; Lv, P.; Liu, X.; Zhu, M.; Qiu, X. microRNA-214 enhances the invasion ability of breast cancer cells by targeting p53. Int. J. Mol. Med. 2015, 35, 1395-1402. [CrossRef]

72. Qiang, R.; Wang, F.; Shi, L.Y.; Liu, M.; Chen, S.; Wan, H.Y.; Li, Y.X.; Li, X.; Gao, S.Y.; Sun, B.C.; et al. Plexin-B1 is a target of miR-214 in cervical cancer and promotes the growth and invasion of HeLa cells. Int. J. Biochem. Cell Biol. 2011, 43, 632-641. [CrossRef] [PubMed]

73. Xin, R.; Bai, F.; Feng, Y.; Jiu, M.; Liu, X.; Bai, F.; Nie, Y.; Fan, D. MicroRNA-214 promotes peritoneal metastasis through regulating PTEN negatively in gastric cancer. Clin. Res. Hepatol. Gastroenterol. 2016, 40, 748-754. [CrossRef]

74. Zhang, K.; Zhang, M.; Jiang, H.; Liu, F.; Liu, H.; Li, Y. Down-regulation of miR-214 inhibits proliferation and glycolysis in non-small-cell lung cancer cells via down-regulating the expression of hexokinase 2 and pyruvate kinase isozyme M2. Biomed. Pharmacother. 2018, 105, 545-552. [CrossRef] [PubMed]

75. Zhao, C.; Sun, W.; Zhang, P.; Ling, S.; Li, Y.; Zhao, D.; Peng, J.; Wang, A.; Li, Q.; Song, J.; et al. miR-214 promotes osteoclastogenesis by targeting Pten/PI3k/Akt pathway. RNA Biol. 2015, 12, 343-353. [CrossRef]

76. Jindra, P.T.; Bagley, J.; Godwin, J.G.; Iacomini, J. Costimulation-dependent expression of microRNA-214 increases the ability of T cells to proliferate by targeting Pten. J. Immunol. 2010, 185, 990-997. [CrossRef] [PubMed]

77. van Mil, A.; Grundmann, S.; Goumans, M.J.; Lei, Z.; Oerlemans, M.I.; Jaksani, S.; Doevendans, P.A.; Sluijter, J.P. MicroRNA-214 inhibits angiogenesis by targeting Quaking and reducing angiogenic growth factor release. Cardiovasc. Res. 2012, 93, 655-665. [CrossRef] [PubMed]

78. Shu, P.; Fu, H.; Zhao, X.; Wu, C.; Ruan, X.; Zeng, Y.; Liu, W.; Wang, M.; Hou, L.; Chen, P.; et al. MicroRNA-214 modulates neural progenitor cell differentiation by targeting Quaking during cerebral cortex development. Sci. Rep. 2017, 7, 8014. [CrossRef] [PubMed]

79. Zhang, J.; Su, B.; Gong, C.; Xi, Q.; Chao, T. miR-214 promotes apoptosis and sensitizes breast cancer cells to doxorubicin by targeting the RFWD2-p53 cascade. Biochem. Biophys. Res. Commun. 2016, 478, 337-342. [CrossRef] [PubMed]

80. Min, L.; Liu, C.; Kuang, J.; Wu, X.; Zhu, L. miR-214 inhibits epithelial-mesenchymal transition of breast cancer cells via downregulation of RNF8. Acta Biochim. Biophys. Sin. 2019, 51, 791-798. [CrossRef]

81. Wang, Z.; Yin, H.; Zhang, Y.; Feng, Y.; Yan, Z.; Jiang, X.; Bukhari, I.; Iqbal, F.; Cooke, H.J.; Shi, Q. miR-214-mediated downregulation of RNF8 induces chromosomal instability in ovarian cancer cells. Cell Cycle 2014, 13, 3519-3528. [CrossRef] [PubMed]

82. Qiu, Y.Y.; Zhang, Y.W.; Qian, X.F.; Bian, T. miR-371, miR-138, miR-544, miR-145, and miR-214 could modulate Th1/Th2 balance in asthma through the combinatorial regulation of Runx3. Am. J. Transl. Res. 2017, 9, 3184-3199. [PubMed]

83. Tao, Y.; Zhao, Z.; Ma, J.; Dong, L.; Liang, Y.; Li, S.; Mao, Y.; Li, Y.; Zhang, Y. MiR-214-3p regulates the viability, invasion, migration and EMT of TNBC cells by targeting ST6GAL1. Cytotechnology 2019, 71, 1155-1165. [CrossRef] [PubMed]

84. Flynt, A.S.; Li, N.; Thatcher, E.J.; Solnica-Krezel, L.; Patton, J.G. Zebrafish miR-214 modulates Hedgehog signaling to specify muscle cell fate. Nat. Genet. 2007, 39, 259-263. [CrossRef]

85. He, S.; Yang, F.; Yang, M.; An, W.; Maguire, E.M.; Chen, Q.; Xiao, R.; Wu, W.; Zhang, L.; Wang, W.; et al. miR-214-3p-Sufu-GLI1 is a novel regulatory axis controlling inflammatory smooth muscle cell differentiation from stem cells and neointimal hyperplasia. Stem Cell Res. Ther. 2020, 11, 465. [CrossRef]

86. Han, L.C.; Wang, H.; Niu, F.L.; Yan, J.Y.; Cai, H.F. Effect miR-214-3p on proliferation and apoptosis of breast cancer cells by targeting survivin protein. Eur. Rev. Med. Pharmacol. Sci. 2019, 23, 7469-7474.

87. Liu, J.; Li, D.; Dang, L.; Liang, C.; Guo, B.; Lu, C.; He, X.; Cheung, H.Y.; He, B.; Liu, B.; et al. Osteoclastic miR-214 targets TRAF3 to contribute to osteolytic bone metastasis of breast cancer. Sci. Rep. 2017, 7, 40487. [CrossRef] 
88. Yu, X.; Luo, A.; Liu, Y.; Wang, S.; Li, Y.; Shi, W.; Liu, Z.; Qu, X. MiR-214 increases the sensitivity of breast cancer cells to tamoxifen and fulvestrant through inhibition of autophagy. Mol. Cancer 2015, 14, 208. [CrossRef]

89. Duan, Q.; Wang, X.; Gong, W.; Ni, L.; Chen, C.; He, X.; Chen, F.; Yang, L.; Wang, P.; Wang, D.W. ER stress negatively modulates the expression of the miR-199a/214 cluster to regulates tumor survival and progression in human hepatocellular cancer. PLoS ONE 2012, 7, e31518. [CrossRef]

90. Decembrini, S.; Bressan, D.; Vignali, R.; Pitto, L.; Mariotti, S.; Rainaldi, G.; Wang, X.; Evangelista, M.; Barsacchi, G.; Cremisi, F. MicroRNAs couple cell fate and developmental timing in retina. Proc. Natl. Acad. Sci. USA 2009, 106, 21179-21184. [CrossRef]

91. Murphy, E.; Steenbergen, C. Mechanisms underlying acute protection from cardiac ischemia-reperfusion injury. Physiol. Rev. 2008, 88, 581-609. [CrossRef]

92. Imahashi, K.; Pott, C.; Goldhaber, J.I.; Steenbergen, C.; Philipson, K.D.; Murphy, E. Cardiac-specific ablation of the Na+-Ca2+ exchanger confers protection against ischemia/reperfusion injury. Circ. Res. 2005, 97, 916-921. [CrossRef]

93. Tani, M.; Neely, J.R. Role of intracellular Na+ in Ca2+ overload and depressed recovery of ventricular function of reperfused ischemic rat hearts. Possible involvement of $\mathrm{H}+-\mathrm{Na}+$ and Na+-Ca2+ exchange. Circ. Res. 1989, 65, 1045-1056. [CrossRef]

94. Zhang, Z.C.; Li, Y.Y.; Wang, H.Y.; Fu, S.; Wang, X.P.; Zeng, M.S.; Zeng, Y.X.; Shao, J.Y. Knockdown of miR-214 promotes apoptosis and inhibits cell proliferation in nasopharyngeal carcinoma. PLoS ONE 2014, 9, e86149. [CrossRef]

95. Vila-Petroff, M.; Salas, M.A.; Said, M.; Valverde, C.A.; Sapia, L.; Portiansky, E.; Hajjar, R.J.; Kranias, E.G.; Mundiña-Weilenmann, C.; Mattiazzi, A. CaMKII inhibition protects against necrosis and apoptosis in irreversible ischemia-reperfusion injury. Cardiovasc. Res. 2007, 73, 689-698. [CrossRef]

96. Hampton, T.G.; Wang, J.F.; DeAngelis, J.; Amende, I.; Philipson, K.D.; Morgan, J.P. Enhanced gene expression of Na(+)/Ca(2+) exchanger attenuates ischemic and hypoxic contractile dysfunction. Am. J. Physiol. Heart Circ. Physiol. 2000, 279, H2846-H2854. [CrossRef]

97. Studer, R.; Reinecke, H.; Bilger, J.; Eschenhagen, T.; Böhm, M.; Hasenfuss, G.; Just, H.; Holtz, J.; Drexler, H. Gene expression of the cardiac $\mathrm{Na}(+)-\mathrm{Ca} 2+$ exchanger in end-stage human heart failure. Circ. Res. 1994, 75, 443-453. [CrossRef]

98. Zhou, T.; Chuang, C.C.; Zuo, L. Molecular Characterization of Reactive Oxygen Species in Myocardial Ischemia-Reperfusion Injury. BioMed Res. Int. 2015, 2015, 864946. [CrossRef]

99. Halestrap, A.P. What is the mitochondrial permeability transition pore? J. Mol. Cell. Cardiol. 2009, 46, 821-831. [CrossRef] [PubMed]

100. Chen, Q.; Vazquez, E.J.; Moghaddas, S.; Hoppel, C.L.; Lesnefsky, E.J. Production of reactive oxygen species by mitochondria: Central role of complex III. J. Biol. Chem. 2003, 278, 36027-36031. [CrossRef]

101. Chen, Q.; Moghaddas, S.; Hoppel, C.L.; Lesnefsky, E.J. Ischemic defects in the electron transport chain increase the production of reactive oxygen species from isolated rat heart mitochondria. Am. J. Physiol. Cell Physiol. 2008, 294, C460-C466. [CrossRef]

102. Zhu, X.; Zuo, L. Characterization of oxygen radical formation mechanism at early cardiac ischemia. Cell Death Dis. 2013, 4, e787. [CrossRef] [PubMed]

103. Cheng, Y.; Liu, X.; Zhang, S.; Lin, Y.; Yang, J.; Zhang, C. MicroRNA-21 protects against the H(2)O(2)-induced injury on cardiac myocytes via its target gene PDCD4. J. Mol. Cell. Cardiol. 2009, 47, 5-14. [CrossRef]

104. Maes, O.C.; An, J.; Sarojini, H.; Wang, E. Murine microRNAs implicated in liver functions and aging process. Mech. Ageing Dev. 2008, 129, 534-541. [CrossRef]

105. Li, J.; Yen, C.; Liaw, D.; Podsypanina, K.; Bose, S.; Wang, S.I.; Puc, J.; Miliaresis, C.; Rodgers, L.; McCombie, R.; et al. PTEN, a putative protein tyrosine phosphatase gene mutated in human brain, breast, and prostate cancer. Science 1997, 275, 1943-1947. [CrossRef]

106. Tamura, M.; Gu, J.; Matsumoto, K.; Aota, S.; Parsons, R.; Yamada, K.M. Inhibition of cell migration, spreading, and focal adhesions by tumor suppressor PTEN. Science 1998, 280, 1614-1617. [CrossRef]

107. Zheng, H.C.; Li, Y.L.; Sun, J.M.; Yang, X.F.; Li, X.H.; Jiang, W.G.; Zhang, Y.C.; Xin, Y. Growth, invasion, metastasis, differentiation, angiogenesis and apoptosis of gastric cancer regulated by expression of PTEN encoding products. World J. Gastroenterol. 2003, 9, 1662-1666. [CrossRef]

108. Sayed, D.; Hong, C.; Chen, I.Y.; Lypowy, J.; Abdellatif, M. MicroRNAs play an essential role in the development of cardiac hypertrophy. Circ. Res. 2007, 100, 416-424. [CrossRef]

109. Cheng, Y.; Ji, R.; Yue, J.; Yang, J.; Liu, X.; Chen, H.; Dean, D.B.; Zhang, C. MicroRNAs are aberrantly expressed in hypertrophic heart: Do they play a role in cardiac hypertrophy? Am. J. Pathol. 2007, 170, 1831-1840. [CrossRef]

110. Oka, T.; Akazawa, H.; Naito, A.T.; Komuro, I. Angiogenesis and cardiac hypertrophy: Maintenance of cardiac function and causative roles in heart failure. Circ. Res. 2014, 114, 565-571. [CrossRef]

111. Chan, L.S.; Yue, P.Y.; Mak, N.K.; Wong, R.N. Role of microRNA-214 in ginsenoside-Rg1-induced angiogenesis. Eur. J. Pharm. Sci. 2009, 38, 370-377. [CrossRef] [PubMed]

112. Souders, C.A.; Bowers, S.L.; Baudino, T.A. Cardiac fibroblast: The renaissance cell. Circ. Res. 2009, 105, 1164-1176. [CrossRef] [PubMed]

113. Porter, K.E.; Turner, N.A. Cardiac fibroblasts: At the heart of myocardial remodeling. Pharmacol. Ther. 2009, 123, 255-278. [CrossRef]

114. Cleutjens, J.P.; Verluyten, M.J.; Smiths, J.F.; Daemen, M.J. Collagen remodeling after myocardial infarction in the rat heart. Am. J. Pathol. 1995, 147, 325-338. 
115. Kong, P.; Christia, P.; Frangogiannis, N.G. The pathogenesis of cardiac fibrosis. Cell. Mol. Life Sci. 2014, 71, 549-574. [CrossRef]

116. Iwanaga, Y.; Aoyama, T.; Kihara, Y.; Onozawa, Y.; Yoneda, T.; Sasayama, S. Excessive activation of matrix metalloproteinases coincides with left ventricular remodeling during transition from hypertrophy to heart failure in hypertensive rats. J. Am. Coll. Cardiol. 2002, 39, 1384-1391. [CrossRef]

117. Turner, N.A.; Das, A.; Warburton, P.; O’Regan, D.J.; Ball, S.G.; Porter, K.E. Interleukin-1 $\alpha$ stimulates pro-inflammatory cytokine expression in human cardiac myofibroblasts. Am. J. Physiol. Heart Circ. Physiol. 2009, 297, H1117-H1127. [CrossRef]

118. Turner, N.A.; Mughal, R.S.; Warburton, P.; O’Regan, D.J.; Ball, S.G.; Porter, K.E. Mechanism of TNF $\alpha$-induced IL-1 $\alpha$, IL-1 $\beta$ and IL-6 expression in human cardiac fibroblasts: Effects of statins and thiazolidinediones. Cardiovasc. Res. 2007, 76, 81-90. [CrossRef] [PubMed]

119. Siwik, D.A.; Chang, D.L.; Colucci, W.S. Interleukin- $1 \beta$ and tumor necrosis factor- $\alpha$ decrease collagen synthesis and increase matrix metalloproteinase activity in cardiac fibroblasts in vitro. Circ. Res. 2000, 86, 1259-1265. [CrossRef]

120. Siwik, D.A.; Pagano, P.J.; Colucci, W.S. Oxidative stress regulates collagen synthesis and matrix metalloproteinase activity in cardiac fibroblasts. Am. J. Physiol. Cell Physiol. 2001, 280, C53-C60. [CrossRef]

121. Hou, Y.; Sun, Y.; Shan, H.; Li, X.; Zhang, M.; Zhou, X.; Xing, S.; Sun, H.; Chu, W.; Qiao, G.; et al. $\beta$-adrenoceptor regulates miRNA expression in rat heart. Med. Sci. Monit. 2012, 18, Br309-Br314. [CrossRef] [PubMed]

122. Liu, N.; Xing, R.; Yang, C.; Tian, A.; Lv, Z.; Sun, N.; Gao, X.; Zhang, Y.; Li, Z. HIP-55/DBNL-dependent regulation of adrenergic receptor mediates the ERK1/2 proliferative pathway. Mol. Biosyst. 2014, 10, 1932-1939. [CrossRef] [PubMed]

123. Bisognano, J.D.; Weinberger, H.D.; Bohlmeyer, T.J.; Pende, A.; Raynolds, M.V.; Sastravaha, A.; Roden, R.; Asano, K.; Blaxall, B.C.; Wu, S.C.; et al. Myocardial-directed overexpression of the human beta(1)-adrenergic receptor in transgenic mice. J. Mol. Cell. Cardiol. 2000, 32, 817-830. [CrossRef] [PubMed]

124. Denby, L.; Ramdas, V.; Lu, R.; Conway, B.R.; Grant, J.S.; Dickinson, B.; Aurora, A.B.; McClure, J.D.; Kipgen, D.; Delles, C.; et al MicroRNA-214 antagonism protects against renal fibrosis. J. Am. Soc. Nephrol. 2014, 25, 65-80. [CrossRef]

125. Bray, F.; Ferlay, J.; Soerjomataram, I.; Siegel, R.L.; Torre, L.A.; Jemal, A. Global cancer statistics 2018: GLOBOCAN estimates of incidence and mortality worldwide for 36 cancers in 185 countries. CA Cancer J. Clin. 2018, 68, 394-424. [CrossRef] [PubMed]

126. Rawla, P.; Barsouk, A. Epidemiology of gastric cancer: Global trends, risk factors and prevention. Prz. Gastroenterol. 2019, 14, 26-38. [CrossRef]

127. Ueda, T.; Volinia, S.; Okumura, H.; Shimizu, M.; Taccioli, C.; Rossi, S.; Alder, H.; Liu, C.G.; Oue, N.; Yasui, W.; et al. Relation between microRNA expression and progression and prognosis of gastric cancer: A microRNA expression analysis. Lancet Oncol. 2010, 11, 136-146. [CrossRef]

128. Akyala, A.I.; Peppelenbosch, M.P. Gastric cancer and Hedgehog signaling pathway: Emerging new paradigms. Genes Cancer 2018, 9, 1-10. [CrossRef]

129. Marin, J.J.; Al-Abdulla, R.; Lozano, E.; Briz, O.; Bujanda, L.; Banales, J.M.; Macias, R.I. Mechanisms of Resistance to Chemotherapy in Gastric Cancer. Anti-Cancer Agents Med. Chem. 2016, 16, 318-334. [CrossRef] [PubMed]

130. Wang, X.; Zhang, H.; Bai, M.; Ning, T.; Ge, S.; Deng, T.; Liu, R.; Zhang, L.; Ying, G.; Ba, Y. Exosomes Serve as Nanoparticles to Deliver Anti-miR-214 to Reverse Chemoresistance to Cisplatin in Gastric Cancer. Mol. Ther. 2018, 26, 774-783. [CrossRef] [PubMed]

131. Romero-Ramirez, L.; Cao, H.; Nelson, D.; Hammond, E.; Lee, A.H.; Yoshida, H.; Mori, K.; Glimcher, L.H.; Denko, N.C.; Giaccia, A.J.; et al. XBP1 is essential for survival under hypoxic conditions and is required for tumor growth. Cancer Res. 2004, 64, 5943-5947. [CrossRef]

132. Lee, A.H.; Iwakoshi, N.N.; Anderson, K.C.; Glimcher, L.H. Proteasome inhibitors disrupt the unfolded protein response in myeloma cells. Proc. Natl. Acad. Sci. USA 2003, 100, 9946-9951. [CrossRef]

133. Qiao, L.; Zhang, H.; Yu, J.; Francisco, R.; Dent, P.; Ebert, M.P.; Röcken, C.; Farrell, G. Constitutive activation of NF-kappaB in human hepatocellular carcinoma: Evidence of a cytoprotective role. Hum. Gene Ther. 2006, 17, 280-290. [CrossRef]

134. Koong, A.C.; Chen, E.Y.; Giaccia, A.J. Hypoxia causes the activation of nuclear factor kappa B through the phosphorylation of I kappa B alpha on tyrosine residues. Cancer Res. 1994, 54, 1425-1430. [PubMed]

135. Nhieu, J.T.; Renard, C.A.; Wei, Y.; Cherqui, D.; Zafrani, E.S.; Buendia, M.A. Nuclear accumulation of mutated beta-catenin in hepatocellular carcinoma is associated with increased cell proliferation. Am. J. Pathol. 1999, 155, 703-710. [CrossRef]

136. Momenimovahed, Z.; Tiznobaik, A.; Taheri, S.; Salehiniya, H. Ovarian cancer in the world: Epidemiology and risk factors. Int. J. Women's Health 2019, 11, 287-299. [CrossRef]

137. Iorio, M.V.; Visone, R.; Di Leva, G.; Donati, V.; Petrocca, F.; Casalini, P.; Taccioli, C.; Volinia, S.; Liu, C.G.; Alder, H.; et al. MicroRNA signatures in human ovarian cancer. Cancer Res. 2007, 67, 8699-8707. [CrossRef]

138. Martinez, I.; Gardiner, A.S.; Board, K.F.; Monzon, F.A.; Edwards, R.P.; Khan, S.A. Human papillomavirus type 16 reduces the expression of microRNA-218 in cervical carcinoma cells. Oncogene 2008, 27, 2575-2582. [CrossRef]

139. Wang, X.; Tang, S.; Le, S.Y.; Lu, R.; Rader, J.S.; Meyers, C.; Zheng, Z.M. Aberrant expression of oncogenic and tumor-suppressive microRNAs in cervical cancer is required for cancer cell growth. PLoS ONE 2008, 3, e2557. [CrossRef]

140. Morgan, E.L.; Scarth, J.A.; Patterson, M.R.; Wasson, C.W.; Hemingway, G.C.; Barba-Moreno, D.; Macdonald, A. E6-mediated activation of JNK drives EGFR signalling to promote proliferation and viral oncoprotein expression in cervical cancer. Cell Death Differ. 2021, 28, 1669-1687. [CrossRef] [PubMed] 
141. Prickett, T.D.; Brautigan, D.L. Cytokine activation of p38 mitogen-activated protein kinase and apoptosis is opposed by alpha-4 targeting of protein phosphatase 2A for site-specific dephosphorylation of MEK3. Mol. Cell. Biol. 2007, 27, 4217-4227. [CrossRef] [PubMed]

142. Lee, J.W.; Choi, C.H.; Choi, J.J.; Park, Y.A.; Kim, S.J.; Hwang, S.Y.; Kim, W.Y.; Kim, T.J.; Lee, J.H.; Kim, B.G.; et al. Altered MicroRNA expression in cervical carcinomas. Clin. Cancer Res. 2008, 14, 2535-2542. [CrossRef] [PubMed]

143. Yang, D.D.; Salciccioli, J.D.; Marshall, D.C.; Sheri, A.; Shalhoub, J. Trends in malignant melanoma mortality in 31 countries from 1985 to 2015. Br. J. Dermatol. 2020, 183, 1056-1064. [CrossRef]

144. Leonardi, G.C.; Falzone, L.; Salemi, R.; Zanghì, A.; Spandidos, D.A.; McCubrey, J.A.; Candido, S.; Libra, M. Cutaneous melanoma: From pathogenesis to therapy. Int. J. Oncol. 2018, 52, 1071-1080. [CrossRef] [PubMed]

145. Lu, J.; Getz, G.; Miska, E.A.; Alvarez-Saavedra, E.; Lamb, J.; Peck, D.; Sweet-Cordero, A.; Ebert, B.L.; Mak, R.H.; Ferrando, A.A.; et al. MicroRNA expression profiles classify human cancers. Nature 2005, 435, 834-838. [CrossRef]

146. Mueller, D.W.; Rehli, M.; Bosserhoff, A.K. miRNA expression profiling in melanocytes and melanoma cell lines reveals miRNAs associated with formation and progression of malignant melanoma. J. Investig. Dermatol. 2009, 129, 1740-1751. [CrossRef]

147. Worley, L.A.; Long, M.D.; Onken, M.D.; Harbour, J.W. Micro-RNAs associated with metastasis in uveal melanoma identified by multiplexed microarray profiling. Melanoma Res. 2008, 18, 184-190. [CrossRef]

148. Segura, M.F.; Belitskaya-Lévy, I.; Rose, A.E.; Zakrzewski, J.; Gaziel, A.; Hanniford, D.; Darvishian, F.; Berman, R.S.; Shapiro, R.L.; Pavlick, A.C.; et al. Melanoma MicroRNA signature predicts post-recurrence survival. Clin. Cancer Res. 2010, 16, 1577-1586. [CrossRef] [PubMed]

149. Mitchell, K.; Svenson, K.B.; Longmate, W.M.; Gkirtzimanaki, K.; Sadej, R.; Wang, X.; Zhao, J.; Eliopoulos, A.G.; Berditchevski, F.; Dipersio, C.M. Suppression of integrin alpha3beta1 in breast cancer cells reduces cyclooxygenase- 2 gene expression and inhibits tumorigenesis, invasion, and cross-talk to endothelial cells. Cancer Res. 2010, 70, 6359-6367. [CrossRef]

150. Penna, E.; Orso, F.; Cimino, D.; Vercellino, I.; Grassi, E.; Quaglino, E.; Turco, E.; Taverna, D. miR-214 coordinates melanoma progression by upregulating ALCAM through TFAP2 and miR-148b downmodulation. Cancer Res. 2013, 73, 4098-4111. [CrossRef]

151. Maemondo, M.; Inoue, A.; Kobayashi, K.; Sugawara, S.; Oizumi, S.; Isobe, H.; Gemma, A.; Harada, M.; Yoshizawa, H.; Kinoshita, I.; et al. Gefitinib or chemotherapy for non-small-cell lung cancer with mutated EGFR. N. Engl. J. Med. 2010, 362, $2380-2388$. [CrossRef] [PubMed]

152. Zhou, C.; Wu, Y.L.; Chen, G.; Feng, J.; Liu, X.Q.; Wang, C.; Zhang, S.; Wang, J.; Zhou, S.; Ren, S.; et al. Erlotinib versus chemotherapy as first-line treatment for patients with advanced EGFR mutation-positive non-small-cell lung cancer (OPTIMAL, CTONG-0802): A multicentre, open-label, randomised, phase 3 study. Lancet Oncol. 2011, 12, 735-742. [CrossRef]

153. Yanaihara, N.; Caplen, N.; Bowman, E.; Seike, M.; Kumamoto, K.; Yi, M.; Stephens, R.M.; Okamoto, A.; Yokota, J.; Tanaka, T.; et al. Unique microRNA molecular profiles in lung cancer diagnosis and prognosis. Cancer Cell 2006, 9, 189-198. [CrossRef]

154. Zhang, Y.; Li, M.; Hu, C. Exosomal transfer of miR-214 mediates gefitinib resistance in non-small cell lung cancer. Biochem. Biophys. Res. Commun. 2018, 507, 457-464. [CrossRef] [PubMed]

155. Ren, H.; Chu, Z.; Mao, L. Antibodies targeting hepatoma-derived growth factor as a novel strategy in treating lung cancer. Mol. Cancer Ther. 2009, 8, 1106-1112. [CrossRef] [PubMed]

156. Liu, C.; Luo, J.; Zhao, Y.T.; Wang, Z.Y.; Zhou, J.; Huang, S.; Huang, J.N.; Long, H.X.; Zhu, B. TWIST1 upregulates miR-214 to promote epithelial-to-mesenchymal transition and metastasis in lung adenocarcinoma. Int. J. Mol. Med. 2018, 42, 461-470. [CrossRef] [PubMed]

157. Sadighparvar, S.; Targhazeh, N.; Karimian, A.; Shafiei-Irannejad, V.; Farsad-Akhtar, N.; Rafieian, S.; Salamati, A.; Bastami, M.; Kafil, H.S.; Yousefi, M.; et al. Downregulation of microRNA-214 and PTEN in tissue samples of patients with breast cancer. Meta Gene 2020, 24, 100668. [CrossRef]

158. Liu, B.; Tian, Y.; Li, F.; Zhao, Z.; Jiang, X.; Zhai, C.; Han, X.; Zhang, L. Tumor-suppressing roles of miR-214 and miR-218 in breast cancer. Oncol. Rep. 2016, 35, 3178-3184. [CrossRef]

159. Kalniete, D.; Nakazawa-Miklaševiča, M.; Štrumfa, I.; Ābolinš, A.; Irmejs, A.; Gardovskis, J.; Miklaševičs, E. High expression of miR-214 is associated with a worse disease-specific survival of the triple-negative breast cancer patients. Hered. Cancer Clin. Prac. 2015, 13, 7. [CrossRef] [PubMed]

160. Dettori, D.; Orso, F.; Penna, E.; Baruffaldi, D.; Brundu, S.; Maione, F.; Turco, E.; Giraudo, E.; Taverna, D. Therapeutic Silencing of miR-214 Inhibits Tumor Progression in Multiple Mouse Models. Mol. Ther. 2018, 26, 2008-2018. [CrossRef]

161. Chen, X.; Wang, Z.; Duan, N.; Zhu, G.; Schwarz, E.M.; Xie, C. Osteoblast-osteoclast interactions. Connect. Tissue Res. 2018, 59, 99-107. [CrossRef]

162. Li, Z.; Hassan, M.Q.; Volinia, S.; van Wijnen, A.J.; Stein, J.L.; Croce, C.M.; Lian, J.B.; Stein, G.S. A microRNA signature for a BMP2-induced osteoblast lineage commitment program. Proc. Natl. Acad. Sci. USA 2008, 105, 13906-13911. [CrossRef]

163. Mizuno, Y.; Yagi, K.; Tokuzawa, Y.; Kanesaki-Yatsuka, Y.; Suda, T.; Katagiri, T.; Fukuda, T.; Maruyama, M.; Okuda, A.; Amemiya, T.; et al. miR-125b inhibits osteoblastic differentiation by down-regulation of cell proliferation. Biochem. Biophys. Res. Commun. 2008, 368, 267-272. [CrossRef] [PubMed]

164. Li, H.; Xie, H.; Liu, W.; Hu, R.; Huang, B.; Tan, Y.F.; Xu, K.; Sheng, Z.F.; Zhou, H.D.; Wu, X.P.; et al. A novel microRNA targeting HDAC5 regulates osteoblast differentiation in mice and contributes to primary osteoporosis in humans. J. Clin. Investig. 2009, 119, 3666-3677. [CrossRef] 
165. Tohmonda, T.; Miyauchi, Y.; Ghosh, R.; Yoda, M.; Uchikawa, S.; Takito, J.; Morioka, H.; Nakamura, M.; Iwawaki, T.; Chiba, K.; et al. The IRE1 $\alpha$-XBP1 pathway is essential for osteoblast differentiation through promoting transcription of Osterix. EMBO Rep. 2011, 12, 451-457. [CrossRef]

166. Bonewald, L.F. The amazing osteocyte. J. Bone Miner. Res. 2011, 26, 229-238. [CrossRef]

167. Yuan, Y.; Guo, J.; Zhang, L.; Tong, X.; Zhang, S.; Zhou, X.; Zhang, M.; Chen, X.; Lei, L.; Li, H.; et al. MiR-214 Attenuates the Osteogenic Effects of Mechanical Loading on Osteoblasts. Int. J. Sports Med. 2019, 40, 931-940. [PubMed]

168. Wang, X.; Li, X.; Li, J.; Zhai, L.; Liu, D.; Abdurahman, A.; Zhang, Y.; Yokota, H.; Zhang, P. Mechanical loading stimulates bone angiogenesis through enhancing type $\mathrm{H}$ vessel formation and downregulating exosomal miR-214-3p from bone marrow-derived mesenchymal stem cells. FASEB J. 2021, 35, e21150. [CrossRef] [PubMed]

169. Li, K.C.; Chang, Y.H.; Hsu, M.N.; Lo, S.C.; Li, W.H.; Hu, Y.C. Baculovirus-Mediated miR-214 Knockdown Shifts Osteoporotic ASCs Differentiation and Improves Osteoporotic Bone Defects Repair. Sci. Rep. 2017, 7, 16225. [CrossRef]

170. Wang, C.G.; Wang, L.; Yang, T.; Su, S.L.; Hu, Y.H.; Zhong, D. Pseudogene PTENP1 sponges miR-214 to regulate the expression of PTEN to modulate osteoclast differentiation and attenuate osteoporosis. Cytotherapy 2020, 22, 412-423. [CrossRef] [PubMed]

171. Cai, M.; Yang, L.; Zhang, S.; Liu, J.; Sun, Y.; Wang, X. A bone-resorption surface-targeting nanoparticle to deliver anti-miR214 for osteoporosis therapy. Int. J. Nanomed. 2017, 12, 7469-7482. [CrossRef] [PubMed]

172. Li, N.; Bai, Y.; Zhou, G.; Ma, Y.; Tan, M.; Qiao, F.; Li, X.; Shen, M.; Song, X.; Zhao, X.; et al. miR-214 Attenuates Aortic Valve Calcification by Regulating Osteogenic Differentiation of Valvular Interstitial Cells. Mol. Ther. Nucleic Acids 2020, 22, 971-980. [CrossRef]

173. Horak, M.; Novak, J.; Bienertova-Vasku, J. Muscle-specific microRNAs in skeletal muscle development. Dev. Biol. 2016, 410, 1-13. [CrossRef]

174. O'Rourke, J.R.; Georges, S.A.; Seay, H.R.; Tapscott, S.J.; McManus, M.T.; Goldhamer, D.J.; Swanson, M.S.; Harfe, B.D. Essential role for Dicer during skeletal muscle development. Dev. Biol. 2007, 311, 359-368. [CrossRef] [PubMed]

175. Huang, T.H.; Zhu, M.J.; Li, X.Y.; Zhao, S.H. Discovery of porcine microRNAs and profiling from skeletal muscle tissues during development. PLoS ONE 2008, 3, e3225. [CrossRef] [PubMed]

176. Honardoost, M.; Soleimani, M.; Arefian, E.; Sarookhani, M.R. Expression Change of miR-214 and miR-135 during Muscle Differentiation. Cell J. 2015, 17, 461-470.

177. Chen, H.; Shalom-Feuerstein, R.; Riley, J.; Zhang, S.D.; Tucci, P.; Agostini, M.; Aberdam, D.; Knight, R.A.; Genchi, G.; Nicotera, P.; et al. miR-7 and miR-214 are specifically expressed during neuroblastoma differentiation, cortical development and embryonic stem cells differentiation, and control neurite outgrowth in vitro. Biochem. Biophys. Res. Commun. 2010, 394, 921-927. [CrossRef] [PubMed]

178. Liu, J.; Githinji, J.; McLaughlin, B.; Wilczek, K.; Nolta, J. Role of miRNAs in neuronal differentiation from human embryonic stem cell-derived neural stem cells. Stem Cell Rev. Rep. 2012, 8, 1129-1137. [CrossRef]

179. Ahmadian-Elmi, M.; Bidmeshki Pour, A.; Naghavian, R.; Ghaedi, K.; Tanhaei, S.; Izadi, T.; Nasr-Esfahani, M.H. miR-27a and miR-214 exert opposite regulatory roles in Th17 differentiation via mediating different signaling pathways in peripheral blood CD4+ T lymphocytes of patients with relapsing-remitting multiple sclerosis. Immunogenetics 2016, 68, 43-54. [CrossRef]

180. Bonneau, E.; Neveu, B.; Kostantin, E.; Tsongalis, G.J.; De Guire, V. How close are miRNAs from clinical practice? A perspective on the diagnostic and therapeutic market. Electron. J. Int. Fed. Clin. Chem. Lab. Med. 2019, 30, 114-127.

181. Ramalingam, H.; Yheskel, M.; Patel, V. Modulation of polycystic kidney disease by non-coding RNAs. Cell Signal. 2020, $71,109548$. [CrossRef] [PubMed]

182. Gallant-Behm, C.L.; Piper, J.; Lynch, J.M.; Seto, A.G.; Hong, S.J.; Mustoe, T.A.; Maari, C.; Pestano, L.A.; Dalby, C.M.; Jackson, A.L.; et al. A MicroRNA-29 Mimic (Remlarsen) Represses Extracellular Matrix Expression and Fibroplasia in the Skin. J. Investig. Dermatol. 2019, 139, 1073-1081. [CrossRef] [PubMed] 